\title{
Comparison of GIS-based AHP and fuzzy AHP methods for hospital site selection: a case study for Prayagraj City, India
}

\author{
Ashutosh Kumar Tripathi $(\mathbb{D} \cdot$ Sonam Agrawal - Rajan Dev Gupta
}

Accepted: 20 May 2021 / Published online: 28 May 2021

(C) The Author(s), under exclusive licence to Springer Nature B.V. 2021

\begin{abstract}
Identification of hospital sites and their ranking is important for the planning and development of any country's health infrastructure. The site selection problem is a typical multi-criteria decision making problem involving multiple stakeholders and their interests. Multi-Criteria Decision Analysis (MCDA) is a promising approach to solve a location-based problem due to the constitution of various criteria involved in decision making. In this research, eleven criterion are chosen which are classified under three main criteria; socio-economic, geographical and environmental. This research aims to identify the appropriate MCDA method for the selection of a new hospital sites. Here, two MCDA methods named Analytical Hierarchy Process (AHP) and Fuzzy AHP (FAHP) are used. Further, Geographical Information System (GIS) based MCDA methodology is proposed in this paper. The results obtained with both AHP and FAHP methods are compared. This comparison is
\end{abstract}

A. K. Tripathi $(\bowtie) \cdot$ S. Agrawal

GIS Cell, Motilal Nehru National Institute of Technology

Allahabad, Prayagraj, Uttar Pradesh 211004, India

e-mail: rgi1551@mnnit.ac.in

S. Agrawal

e-mail: sonam@mnnit.ac.in

R. D. Gupta

Civil Engineering Department, Motilal Nehru National

Institute of Technology Allahabad, Prayagraj,

Uttar Pradesh 211004, India

e-mail: rdg@mnnit.ac.in based on criterion rankings, proposed hospital locations and sensitivity analysis. The main difference in results is shown in the result of sensitivity analysis in which constant variation in site ranking is obtained when weight change analysis is performed using AHP. The FAHP result shows only one variation in site ranking after a change in weight from +10 to $+20 \%$. The result suggests that FAHP may be a better approach to the hospital site selection problem.

Keywords Hospital site selection - Geographic information system (GIS) · Multi-criteria decision analysis (MCDA) - Analytic hierarchy process (AHP) · Fuzzy AHP (FAHP) · Sensitivity analysis

\section{Introduction}

Over the period of time, the demand for healthcare facilities has increased exponentially all over the world (Pantzartzis et al., 2017; Velez et al., 2021). Healthcare services play an essential role in the socioeconomic development of any nation. The main aim of health services is to fulfill the need of healthcare facilities to all people at all times (Daskin \& Dean, 2004; Murad, 2007; Tripathi et al., 2020a). The need for healthcare is more pronounced in urban areas where the population increases continuously due to the migration of people from rural areas that resulted in a 
disparity of access to such services (Dell'Ovo et al., 2018; Reath et al., 2019; Shahbod et al., 2020). However, healthcare is often ignored by the governments during budget allocation and infrastructure development. The recent outbreak of COVID-19 pandemic has realized several nations about the pathetic condition of their health infrastructure (Jabaris \& Ananthalakshmi, 2021; Siddiqui et al., 2020). It has reflected the healthcare reality of nations (Caligiuri et al., 2020; Tripathi et al., 2019). For example, the German government was able to save its citizen more than other European Union countries from COVID-19 because of the larger number of hospitals (Zolfani et al., 2020). The mortality and morbidity of this pandemic have highlighted the importance of healthcare access.

More hospitals are needed to be established to improve the healthcare facility. The very first requirement for this is to select the locations of the opening of new hospitals. Site selection of hospitals is an ill structured problem. It has several stakeholders like doctors, medical staff, patients, pharmaceutical representatives and real estate developers. It requires proper coordination between the city planners, government and health-related policy makers (Ahmed et al., 2016; Kahraman et al., 2019; Miç \& Antmen, 2019). Optimal hospital location will help to improve the effectiveness of hospitals' functionality in terms of service provision, delivery and optimization. The selection of undesired locations always leads to a decrease in customer satisfaction and an increase in expenses. Therefore, to meet the need for an adequate healthcare facility, there is a need to plan new optimal hospital sites.

The selection of optimal hospital location depends upon the various criteria. These criteria are heterogeneous in nature and require an optimization method to evaluate them and their effect on each other (Çetinkaya et al., 2016; Erbaş et al., 2018). Therefore, a multidimensional approach to decision making is required that can be fulfilled by the Multi-Criteria Decision Analysis (MCDA) method (Ding et al., 2020; Longaray et al., 2018). Integration of GIS with MCDA can assist the site selection with its spatial extent analysis. This capability helps the planner to make an informative decision on the hospital site selection problem. It will be more appropriate in a situation where the planning instruments do not provide prescriptive guidelines for the decisions. Some studies have been carried out in the selection of optimal hospital locations. These studies have been carried out by different MCDA methods like AnalyticHierarchy Process (AHP), Fuzzy AHP (FAHP), Technique for Order of Preference by Similarity to Ideal Solution (TOPSIS), Fuzzy TOPSIS and Elimination and Choice Expressing Reality (ELECTRE) (Kumar et al., 2016; Rajak \& Shaw, 2019; Senvar et al., 2016; Vahidnia et al., 2009).

In light of the above discussion, the establishment of new hospitals is undoubtedly the need of the hour. Site selection for the hospital is a complex decision that needs to be supported by advanced decision making techniques using GIS. Although some studies are found on this topic, there is a need for more elaborated evaluation of hospital site selection parameters and criteria by involving more stakeholders. Also, a comparative analysis between popular MCDA methods, viz, AHP and FAHP, is required to ascertain which method would be best for the hospital site selection. Many site selection researches have been carried out by fuzzy AHP methods without examining whether it will actually make a significant difference in outcome than traditional AHP. Few studies have done a comparative analysis of AHP and FAHP in site selection (Guler \& Yomralioglu, 2020; Rajak \& Shaw, 2019; Rajasekhar et al., 2019). But these studies are mainly focused on identifying differences in criterion weight, criterion ranking and suitability map, which need to be done extensively in the context of GIS based MCDA. This will help the decision-makers to analyze different perspectives such as criterion weight, criterion ranking, suitability map analysis and identifying the spatial extent of alternative locations. However, no research has found that includes a comparative analysis in hospital site selection. Therefore, it is mandatory to conduct a comparative analysis of the AHP and FAHP approaches for the hospital site selection. This research work is an attempt in this direction.

The main objective of this paper is to compare AHP and FAHP based identification of hospital sites. For this purpose, a four-step method is proposed in this paper. In the first phase, three main-criteria and eleven sub-criteria are determined based on the knowledge of experts and literature survey. The next step involves spatial mapping of criteria using GIS analysis. The third stage is the GIS-based MCDA approach, which involves the prioritization of main-criteria and sub- 
criteria using AHP and FAHP. In the final phase, a site suitability map is created to determine the optimal sites for the hospital. Finally, a critical comparison of the AHP and FAHP-based hospital site selection process is performed. This comparison is based on criteria ranking, location of hospital sites and sensitivity analysis.

\section{Literature review}

MCDA technique for site selection

MCDA provides a set of procedures and techniques to solve complex decision-making problems in a hierarchical manner (Malczewski \& Rinner, 2015). AHP is one of the most common MCDA methods used for site selection (Saaty, 1977, 1990). It analyzes decision making based on deterministic data values. However, sometimes the data are incomplete and complex. Therefore, experts built different opinions from it due to varying perceptions. This creates ambiguity and uncertainty in the decision space. To deal with such uncertainties, a combination of fuzzy set theory and AHP, known as FAHP, is being introduced (Aggarwal \& Singh, 2013). In FAHP, attribute datasets are expressed using a fuzzy membership function that defines the degree of membership value for the interest of the particular attribute.

MCDA technique is frequently used in site selection as it is a multidimensional problem that involves several criteria in decision making. Facility location assessment problems are considered as a critical decision making problem. It is a crucial task for any government to resolve the issue of land acquisition, to avoid undesirable environmental load and to utilize the profitability of the land use (Çetinkaya et al., 2018; Saha \& Agrawal, 2020; Soltani et al., 2019). Site selection aided with GIS technology could play a significant role in the creation of a problem-solving environment for spatially referenced data (Maguire, 1991). Although, GIS and MCDA are two different area of research but their integration could benefit the site selection problem in analyzing the spatial decision and evaluating the ranking of different criteria (Feizizadeh et al., 2014; Tripathi et al., 2020b). Site selection studies like railway station (Mateus et al., 2008; Prasertsri \& Sangpradid, 2020), fire station (Chaudhary et al., 2016; Nyimbili \& Erden, 2020), solar photovoltaic plant (Garni \& Awasthi, 2017; Shorabeh et al., 2019), landfill (Aksoy \& San, 2019; Rahmat et al., 2017) and wastewater disposal (Aydi et al., 2016) proves that MCDA could be the best possible model to solve the location based problems.

Hospital site selection is one of the ill structured problem which is faced by the planners, especially for developing countries like India (Kumar et al., 2016; Mishra et al., 2019). A number of research papers focused on the hospital site selection have been found. These literatures offered different procedures for hospital site selection. For example; Kim et al. (2015), Murad (2007), Ramani et al. (2007) and Schuurman et al. (2008) proposed the GIS-based approach for hospital site selection. But, they do not consider the priority of the criterion affecting to the hospital sites and focus only on GIS-based analysis. Therefore, GIS-based MCDA approach is introduced for the hospital site selection that includes the prioritization of affected criterion along with their spatial distribution. This approach is capable of achieving a transparent and analytical decision making environment for hospital site selection. It can consider various factors which cannot be ignored to get a solution closer to reality. These criteria vary with the location of study area (Senvar et al., 2016; Vahidnia et al., 2009). Critical factors that affect the hospital sites are identified through literature review. These factors are population density, land cost, proximity to road, proximity to railway, pollution and distance to other hospital (Dehe \& Bamford, 2015; Dell'Ovo et al., 2018; Oppio et al., 2016; Rahimi et al., 2017; Senvar et al., 2016; Vahidnia et al., 2009). In addition to the selection of influential criteria, there is a need to know their relation to each other as well as their impact on overall site suitability.

Recent studies adopted several MCDA techniques such as ELECTRE-TRI, ordered weighted averaging, compromise programming, goal programming and AHP for hospital site suitability. Among them, AHP method is used by several researchers (Ahmed et al., 2016; Dell'Ovo et al., 2018; Hariz et al., 2017; Mishra et al., 2019; Rahimi et al., 2017; Soltani et al., 2019). In AHP, numerical values are used to express expert judgment. Such precise comparisons of decisions may be impossible to determine and can therefore lead to ambiguity in many practical implementations. Therefore, many hospital site selection researches use the more advance FAHP approach (Kumar et al., 2016; 
Neisani Samani \& Alesheikh, 2019; Rajak \& Shaw, 2019; Soltani \& Marandi, 2011; Vahidnia et al., 2009).

AHP

AHP is a multi-criteria decision-making approach in which the criteria are organized in a hierarchical structure. In this approach, the relative importance of the criterion is assumed to be based on the AHP scale. This scale is used to direct the decision-maker to construct the Pairwise Comparison Matrix (PCM). The PCM shows whether each element is equally strong, slightly strong, fairly strong, very strong, or absolutely strong than the other elements. These relative intensities are then converted into numerical values, as shown in Table 1.

The following steps are used to identify the criteria weight through the AHP process:

1. From the PCM m $=(\mathrm{n} * \mathrm{n})$ for $\mathrm{n}$ criteria. Let $P_{i j}$ is the value of the cell located at the ith row and jth column of PCM. Then, the scores entered in $P_{i j}$ and $P_{j i}$ should satisfy the constraint in Eq. (1).

$P_{i j} \cdot P_{j i}=1$

2. Calculate the Consistency Ratio (CR) based on Eq. (2). This defines whether the formed PCM is consistent or not. If CR is less than 0.1 , then it is consistent.

$\mathrm{CR}=\frac{\mathrm{CI}}{\mathrm{RI}}$

Here, RI is the Random Index and CI is the Consistent Index, which is calculated using Eq. (3).

Table 1 AHP scale (Saaty, 1977)

\begin{tabular}{ll}
\hline Linguistic terms & $\begin{array}{l}\text { AHP scale } \\
\text { Intensity of importance }\end{array}$ \\
\hline Equally important & 1 \\
Weakly important & 3 \\
Strongly important & 5 \\
Very strongly important & 7 \\
Absolutely important & 9 \\
Intermediate values & $2,4,6,8$ \\
\hline
\end{tabular}

$$
\mathrm{CI}=\frac{\lambda_{\max }-n}{n-1}
$$

Here, $\lambda_{\max }$ is the biggest eigen value of PCM.

3. The normalized matrix is then formed using Eq. (4).

$$
\bar{P}_{i j}=\frac{P_{i j}}{\sum_{i=1}^{n} P_{i j}}
$$

4. In this step, the average across row entries is calculated to obtain the final weights using Eq. (5).

$$
W_{i}=\frac{\sum_{i=1}^{n} \bar{P}_{i j}}{n}
$$

\section{FAHP}

Sometimes dissipation or ambiguity problems arise when creating a comparison matrix. It is not always possible to specify crisp values to compare different criteria. Therefore, FAHP is used so that fuzzy crisp values can be assigned. The following is the working procedure of FAHP.

\section{Generation of comparison matrix}

In FAHP, a linguistic statement is used to compare the two criteria. These linguistic statements are expressed by the Fuzzy Comparison Ratio Scale, as shown in Table 2. This ratio scale is defined as TFN, namely, a triple with the smallest, most probable and largest possible fuzzy values (Ayağ, 2014). These TFNs are

Table 2 FAHP scale (Chang, 1996; Soltani \& Marandi, 2011)

\begin{tabular}{lll}
\hline Linguistic terms & \multicolumn{2}{l}{ FAHP scale } \\
\cline { 2 - 3 } & TFN & Reciprocal TFN \\
\hline Equally important & $(1,1,1)$ & $(1,1,1)$ \\
Weakly important & $(2,3,4)$ & $(1 / 4,1 / 3,1 / 2)$ \\
Strongly important & $(4,5,6)$ & $(1 / 6,1 / 5,1 / 4)$ \\
Very strongly important & $(6,7,8)$ & $(1 / 8,1 / 7,1 / 6)$ \\
Absolutely important & $(8,9,10)$ & $(1 / 10,1 / 9,1 / 8)$ \\
\hline
\end{tabular}


used to produce fuzzy PCMs in FAHP (Chan et al., 2013).

The fuzzy PCM $\tilde{C}$ for $\mathrm{n}$ criteria or alternatives is defined by Eq. (6) (Chang, 1996; Demirel et al., 2008).

$$
\begin{aligned}
& \tilde{C}=\left(\tilde{C}_{i j}\right)_{n \times n} \\
& =\left[\begin{array}{cccc}
(1,1,1) & \left(l_{12}, m_{12}, u_{12}\right) & \cdots & \left(l_{1 n}, m_{1 n}, u_{1 n}\right) \\
\left(l_{21}, m_{21}, u_{21}\right) & (1,1,1) & \cdots & \left(l_{2 n}, m_{2 n}, u_{2 n}\right) \\
\vdots & \vdots & \ddots & \vdots \\
\left(l_{n 1}, m_{n 1}, u_{n 1}\right) & \left(l_{n 2}, m_{n 2}, u_{n 2}\right) & \cdots & (1,1,1)
\end{array}\right]
\end{aligned}
$$

where $1, \mathrm{~m}$, $\mathrm{u}$ represents the lower, medium and upper bound of the TFN respectively.

$$
\begin{aligned}
& \tilde{C}_{i j}=\left(l_{i j}, m_{i j}, u_{i j}\right) \text { and } \tilde{C}_{i j}^{-1}=\left(1 / u_{i j}, 1 / m_{i j}, 1 / l_{i j}\right) \\
& \text { for } \mathrm{i}, \mathrm{j}=1,2, \ldots \ldots \ldots, \mathrm{n} \text { and } \mathrm{i} \neq \mathrm{j} .
\end{aligned}
$$

\section{Generation of fuzzy weight matrix}

Several approaches are available to generate FAHP weights from pairwise comparison matrix. It produces output as a set of fuzzy weights or crisp weights. Geometric mean method (Buckley, 1985), fuzzy logarithmic least-squares method (Wang et al., 2006), and linear goal programming method (Wang \& Chin, 2008) are some approaches to produce fuzzy weights from PCM. Extent analysis (Chang, 1996) and fuzzy preference programming based nonlinear method (Mikhailov, 2003) are approaches to produce crisp weights. Chang (1996) proposed an extend analysis method which computes the synthetic extend values of the pairwise comparison (Murat et al., 2015). These synthetic extend values, known as weighted values of all parameters, are also available in the form of TFNs. Fuzzy synthetic extent value for the ith criterion is calculated by the Eq. (7) (Chang, 1996).

$$
\begin{aligned}
\tilde{S_{i}} & =\sum_{j=1}^{n} \tilde{a}_{i j} \otimes\left[\sum_{k=1}^{n} \sum_{j=1}^{n} \tilde{a}_{k j}\right]^{-1} \\
& =\left(\frac{\sum_{j=1}^{n} l_{i j}}{\sum_{k=1}^{n} \sum_{j=1}^{n} u_{k j}}, \frac{\sum_{j=1}^{n} m_{i j}}{\sum_{k=1}^{n} \sum_{j=1}^{n} m_{k j}}, \frac{\sum_{j=1}^{n} u_{i j}}{\sum_{k=1}^{n} \sum_{j=1}^{n} l_{k j}}\right)
\end{aligned}
$$

$$
\mathrm{i}=1, \ldots . ., \mathrm{n} \text {. }
$$

where $\otimes$ denotes the extended multiplication of two fuzzy numbers, $\mathrm{j}$ and $\mathrm{k}$ are row and column of the corresponding matrix, respectively.
Generation of crisp weight for each criterion

In this step, the approximation of fuzzy priorities is performed. For this purpose, the degree of possibility between two fuzzy synthetic extent values is calculated. The given equation computes the degree of possibility $\tilde{S_{i}} \geq \tilde{S_{j}}$.

$$
\begin{aligned}
& V\left(\tilde{S_{i}} \geq \tilde{S_{j}}\right)=\sup _{y \geq x}\left[\min \left(\tilde{S_{j}}(x), \tilde{S_{i}}(y)\right)\right] \\
& V\left(\tilde{S_{i}} \geq \tilde{S_{j}}\right)=\left\{\begin{array}{cc}
1 & m_{i} \geq m_{j} \\
\frac{\left(u_{i}-l_{j}\right)}{l_{j} \geq u_{i}} \\
0 & \text { otherwise } \\
0 & i, j=1, \ldots, n ; j \neq i
\end{array}\right.
\end{aligned}
$$

where $\tilde{S_{i}}=\left(l_{i}, m_{i}, u_{i}\right)$ and $\tilde{S_{j}}=\left(l_{j}, m_{j}, u_{j}\right)$.

Finally, the estimation of the priority vector $W=$ $\left(w_{1}, \ldots, w_{n}\right)^{T}$ of a comparison matrix is calculated by using Eq. (9).

$\frac{V\left(\tilde{S_{i}} \geq \tilde{S_{j}} \mid j=1, \ldots, n ; j \neq i\right)}{\sum_{k=1}^{n} V\left(\tilde{S_{k}} \geq \tilde{S_{j}} \mid j=1, \ldots, n ; j \neq k\right)}, \quad i=1, \ldots, n$

The fuzzy weighted vector is calculated by Eq. (10)

$W^{\prime}\left(A_{i}\right)=\left[W^{\prime}\left(A_{1}\right), W^{\prime}\left(A_{2}\right), \ldots, W^{\prime}\left(A_{n}\right)\right]^{T}$

where $A_{i}(i=1,2, \ldots, n)$ are the $n$ criteria. The normal weighted vector is calculated using the normalization procedure.

$W\left(A_{i}\right)=\left[W\left(A_{1}\right), W\left(A_{2}\right), \ldots, W\left(A_{n}\right)\right]^{T}$

\section{Materials}

Study area

Prayagraj city, formerly known as Allahabad city, is one the biggest cities in the State of Uttar Pradesh (U.P.) of India. It has been selected as Smart City by Ministry of Housing and Urban Affairs (MoHUA), Government of India (GoI) in 2015. The Smart Cities Mission is an innovative and new initiative by the GoI to drive economic growth and improve the quality of life of people by providing core 


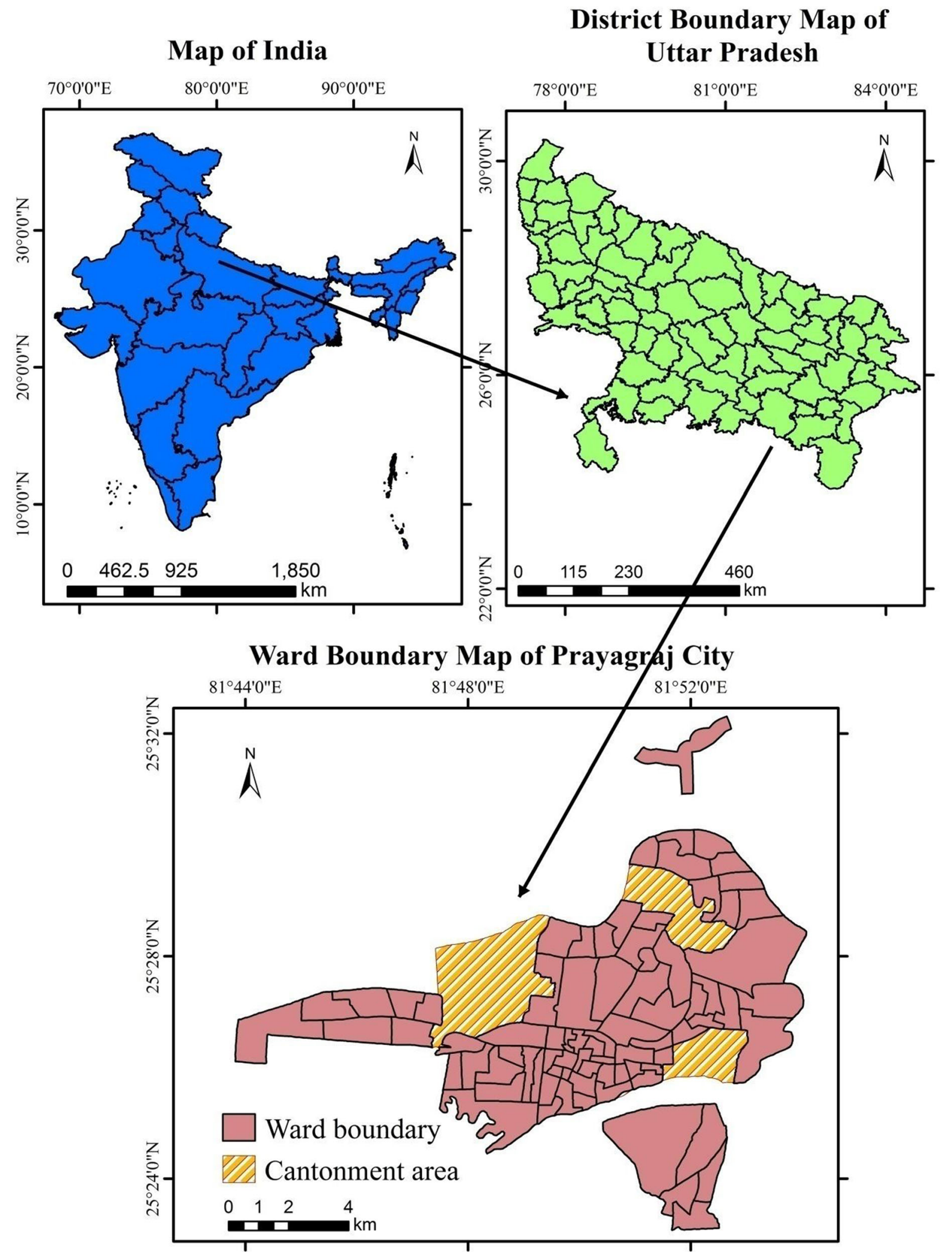


Fig. 1 Study area

infrastructure and harnessing technology to enable the local area development and create smart outcomes for the citizens. Prayagraj city has rapidly evolved in the last three decades due to the urbanization process and there is a need to provide a clean, inclusive and sustainable environment for the development in the city with technological intervention. Due to this, Prayagraj city is selected as the study area for the present work.

Prayagraj city is located in the north-central region of the state of U.P., India and falls in the administrative boundary of Prayagraj district (Fig. 1). The area of Prayagraj city is about $76.29 \mathrm{~km}^{2}$. The total population of the city is $1,112,544$. Prayagraj city has $20 \%$ of the district population and $80 \%$ of the total urban population. The population density of city is 157 person per hectare. According to Prayagraj Municipal Corporation, the city is divided into 80 wards. Ward 76 has the highest population of 25,256 person and ward 78 has the highest population density of 1115 person per hectare.

As per the Ministry of Urban Development (MoUD) report, Prayagraj city has 37 dispensaries (1 for every 15,000 person), 15 small hospitals (1 for every 45,000-1 lakh person) and 12 multi-specialty hospitals (1 for every 1 lakh person). As per norms, there should be 162 dispensaries, 54 small hospitals and 24 multi-specialty hospitals. As per GoI's latest National Family Health Survey (2015-16) just 7.1\% of district households are covered by health insurance or related schemes. There are some key health

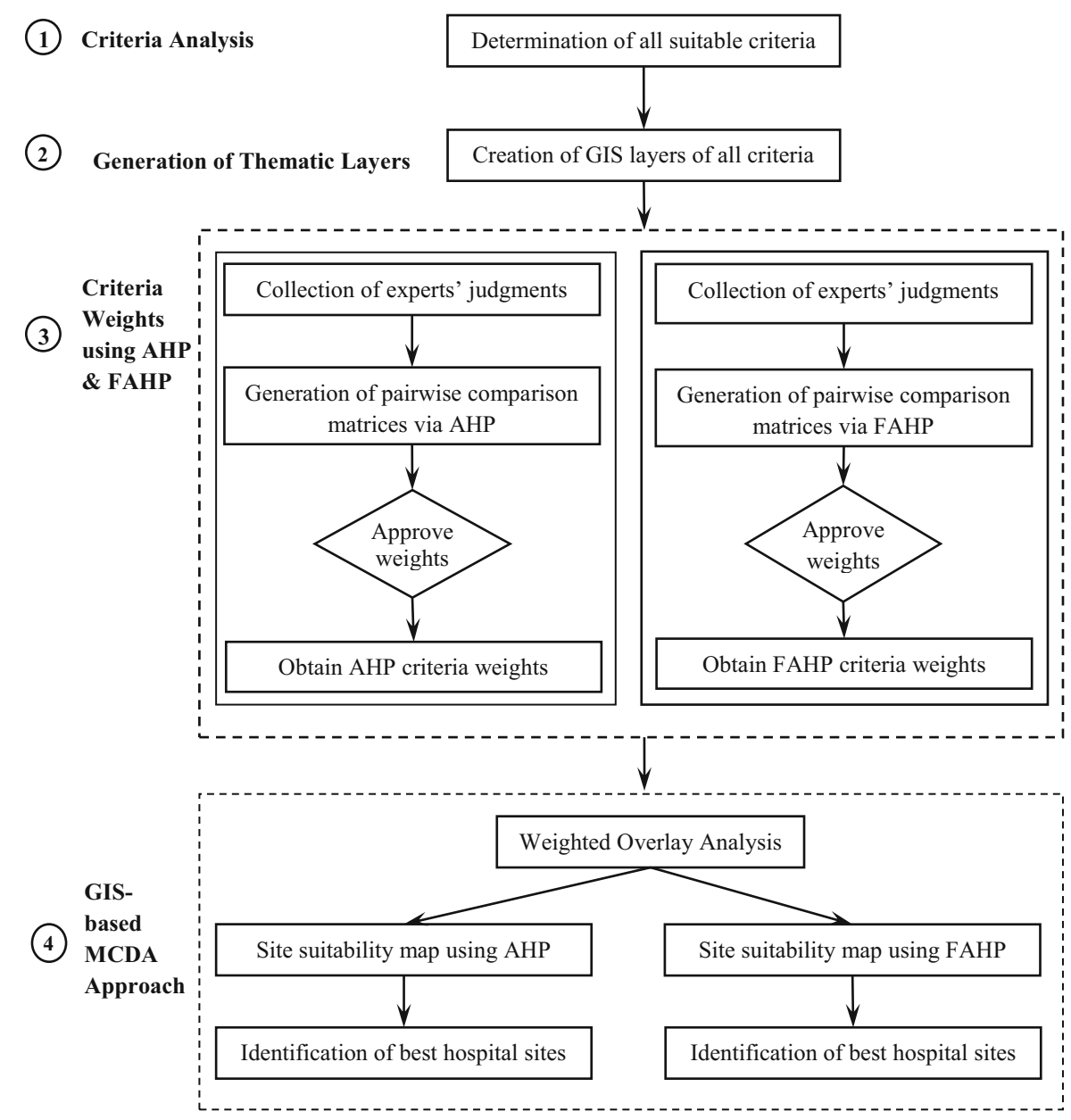

Fig. 2 Methodology to compare and analysis of GIS-based AHP and FAHP for Hospital Site Selection 
Table 3 Description of the evaluation criterion

\begin{tabular}{|c|c|c|c|c|c|c|c|c|c|c|}
\hline $\begin{array}{l}\text { S. } \\
\text { No. }\end{array}$ & Criteria & Definition & $\begin{array}{l}\text { Vahidnia } \\
\text { et al., } \\
2009\end{array}$ & $\begin{array}{l}\text { Dehe \& } \\
\text { Bamford, } \\
2015\end{array}$ & $\begin{array}{l}\text { Senvar } \\
\text { et al., } \\
2016\end{array}$ & $\begin{array}{l}\text { Rahimi } \\
\text { et al., } \\
2017\end{array}$ & $\begin{array}{l}\text { Ovo } \\
\text { et al., } \\
2018 \text {, }\end{array}$ & $\begin{array}{l}\text { Şahin } \\
\text { et al., } \\
2019\end{array}$ & $\begin{array}{l}\text { Soltani \& } \\
\text { Marandi, } \\
2011\end{array}$ & $\begin{array}{l}\text { Ramani } \\
\text { et al., } \\
2007\end{array}$ \\
\hline 1 & $\begin{array}{c}\text { Population } \\
\text { density }\end{array}$ & $\begin{array}{l}\text { Hospital site should be } \\
\text { near to the high } \\
\text { population zones }\end{array}$ & $\sqrt{ }$ & $\sqrt{ }$ & & $\sqrt{ }$ & $\sqrt{ }$ & $\sqrt{ }$ & $\sqrt{ }$ & \\
\hline 2 & $\begin{array}{c}\text { Proximity } \\
\text { to slum }\end{array}$ & $\begin{array}{l}\text { Hospital site should be } \\
\text { near to the slum } \\
\text { location }\end{array}$ & & & & & & & & $\sqrt{ }$ \\
\hline 3 & Land cost & $\begin{array}{l}\text { Hospital site should be } \\
\text { preferably located on } \\
\text { low land cost area }\end{array}$ & $\sqrt{ }$ & $\sqrt{ }$ & $\sqrt{ }$ & & & & & \\
\hline 4 & $\begin{array}{l}\text { Proximity } \\
\text { to road }\end{array}$ & $\begin{array}{l}\text { Hospital site should be } \\
\text { near to the main road } \\
\text { for transportation }\end{array}$ & $\sqrt{ }$ & $\sqrt{ }$ & $\sqrt{ }$ & $\sqrt{ }$ & $\sqrt{ }$ & & $\sqrt{ }$ & $\sqrt{ }$ \\
\hline 5 & $\begin{array}{l}\text { Distance to } \\
\text { other } \\
\text { hospital }\end{array}$ & $\begin{array}{l}\text { New hospital site should } \\
\text { not be very far from } \\
\text { the already available } \\
\text { hospital }\end{array}$ & & & & & & & $\sqrt{ }$ & $\sqrt{ }$ \\
\hline 6 & $\begin{array}{l}\text { Proximity } \\
\text { to } \\
\text { railway }\end{array}$ & $\begin{array}{l}\text { Hospital site should be } \\
\text { near to the railway for } \\
\text { transportation }\end{array}$ & & $\sqrt{ }$ & $\sqrt{ }$ & $\sqrt{ }$ & $\sqrt{ }$ & & & \\
\hline 7 & $\begin{array}{l}\text { Possibility } \\
\text { of } \\
\text { extension }\end{array}$ & $\begin{array}{l}\text { Hospital site should be } \\
\text { located in abandoned } \\
\text { areas where urban } \\
\text { expansion is possible } \\
\text { in the future }\end{array}$ & & $\sqrt{ }$ & $\sqrt{ }$ & $\sqrt{ }$ & & & & \\
\hline 8 & Slope & $\begin{array}{l}\text { Hospital site should be } \\
\text { located in flat area (not } \\
\text { greater than } 7 \% \text { ) }\end{array}$ & & & & & & & $\sqrt{ }$ & $\sqrt{ }$ \\
\hline 9 & $\begin{array}{l}\text { Air } \\
\text { pollution }\end{array}$ & $\begin{array}{l}\text { Hospital site should be } \\
\text { far from where air } \\
\text { quality index is higher, } \\
\text { i.e., air pollution is } \\
\text { high }\end{array}$ & $\sqrt{ }$ & & & $\sqrt{ }$ & & $\sqrt{ }$ & $\sqrt{ }$ & $\sqrt{ }$ \\
\hline 10 & Green area & $\begin{array}{l}\text { Hospital site should be } \\
\text { near to dense } \\
\text { vegetation like trees or } \\
\text { forest }\end{array}$ & & & & $\sqrt{ }$ & & & & \\
\hline 11 & $\begin{array}{l}\text { Unhealthy } \\
\text { industry }\end{array}$ & $\begin{array}{l}\text { Hospital site should be } \\
\text { far from the industrial } \\
\text { area }\end{array}$ & & & & $\sqrt{ }$ & & & & \\
\hline
\end{tabular}

indicators in this survey that can highlight the need of the hospitals in the study area. In the urban area, just $37.9 \%$ of children whose age is $12-23$ months got fully immunized. This immunization includes BCG, measles, three doses of polio vaccine and three doses of DPT vaccine. The anemia condition of children and women is also alarming. In the urban region, $60.7 \%$ children and $55.5 \%$ of women are anemic. Lifestyle diseases are also getting rampant in the urban population. Among the adults of age 15-49 years, 9.5\% are suffering from a higher level of blood sugar while 16.7 are having hypertension. Therefore, new hospitals must be established around the city to fulfill the healthcare requirement of people. 
Fig. 3 Criteria hierarchy for hospital site selection

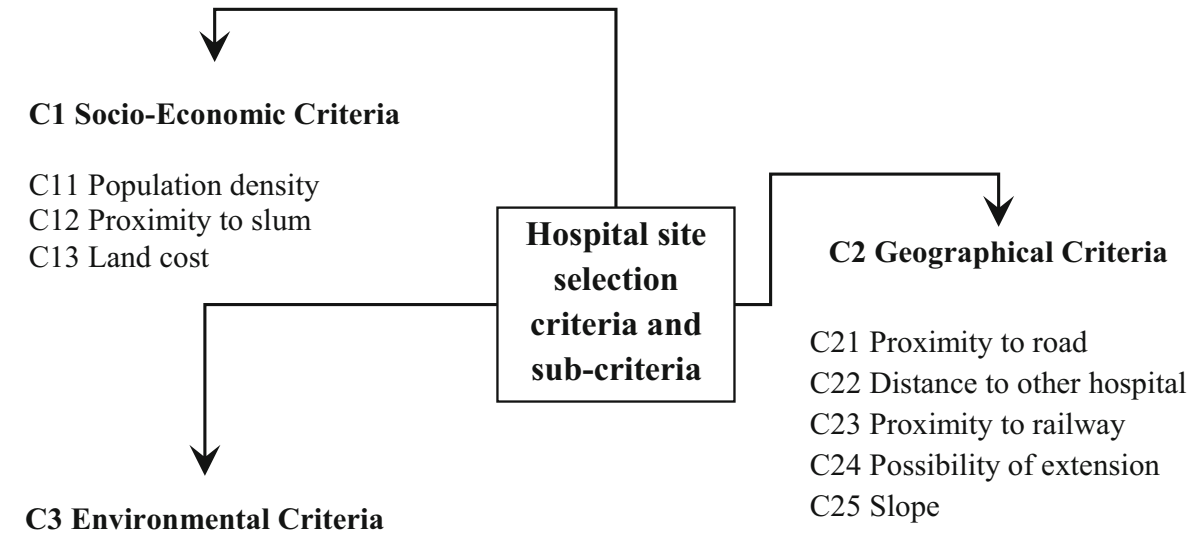

C31 Air pollution

C32 Green area

C33 Unhealthy industry
Data used

To perform the spatial mapping of criteria different type of datasets are collected from different sources. The Survey of India (SOI) is a government agency that is authorized for the distribution of topographic maps in India. A topographic map with Open Series Map number G44P15 is collected from SOI. This topographic map is at the scale of 1:50,000 with WGS-84 datum and UTM projection system. The administrative boundary of Prayagraj city is extracted from the ward boundary map, which is downloaded from the Prayagraj Nagar Nigam website (http://allahabadmc. gov.in/). This map is available at 1:40,233 scale. Here, digitization is performed to create the ward boundary layer of Prayagraj. The geographic location (latitude and longitude) of each hospital is collected using the handheld Global Positioning System (GPS) receiver from the field survey. Field survey is performed using Trimble Juno 3B handheld GPS with 2-5 m real-time accuracy. Air pollution data is collected from the U.P. Pollution Control Board. Population data is collected from the Census-2011 registry. Slum data is collected from the MoHUA, Government of India. Prayagraj Development Authority (PDA) provides the land cost information of the Prayagraj city.

A multispectral image is also collected to create the Land Use/Land Cover (LULC) map of the Prayagraj city. Here, the Sentinel-2A satellite image, acquired on April 4, 2019, is downloaded from the Copernicus programme of the European Space Agency (ESA) website. This multispectral image has a spatial resolution of $10 \mathrm{~m}$ for band 2 (blue), band 3 (green), band 4 (red) and band 8 (near infrared). Image preprocessing and layer stacking is performed to obtain a composite image. The LULC map is then generated by applying the supervised classification technique. The ASTER DEM data, acquired on October $17^{\text {th }}, 2011$ with $30 \mathrm{~m}$ resolution, is downloaded from the USGS website. It helps to generate the slope map of the study area.

\section{Methodology}

The flowchart of the proposed methodology is given in Fig. 2. It is a four-step process, which includes: (1) criterion analysis, (2) GIS analysis, (3) MCDA methods, and (4) GIS-based MCDA analysis. A detailed description of this method is given below.

\section{Criteria analysis}

The first phase involves the analysis and evaluation of criteria that affect the location of the hospital. For this, a board of experts and academicians is created. Experts are local administrators working in various hospitals in the Prayagraj city while academicians are the researchers working in the health service domain. In this research, hospital site selection criteria are evaluated based on the expert's and academician's knowledge and from literature survey. From the relevant literature, it is founded that the criteria used 
Table 4 Spatial data and its associated spatial analysis tool

\begin{tabular}{lllll}
\hline & Criteria & Sub-criteria & Source & Analysis \\
\hline C11 & Socio-Economic & Population density & Census 2011 & Normalization \\
C12 & & Proximity to slum & MoHUA, Government of India & Euclidean distance \\
C13 & & Land cost & Prayagraj Development Authority & Interpolation (IDW) \\
C21 & Geographic & Proximity to road & SOI topographic map & Euclidean distance \\
C22 & & Distance to other hospital & Field survey & Euclidean distance \\
C23 & & Proximity to railway & SOI topographic map & Euclidean distance \\
C24 & & Possibility of extension & ESA & Euclidean distance \\
C25 & & Slope & USGS & Slope \\
C31 & Environmental & Air pollution & U.P. Pollution Control Board & Interpolation (IDW) \\
C32 & & Green area & ESA & Euclidean distance \\
C33 & & Unhealthy industry & SOI topographic map & Euclidean distance \\
\hline
\end{tabular}

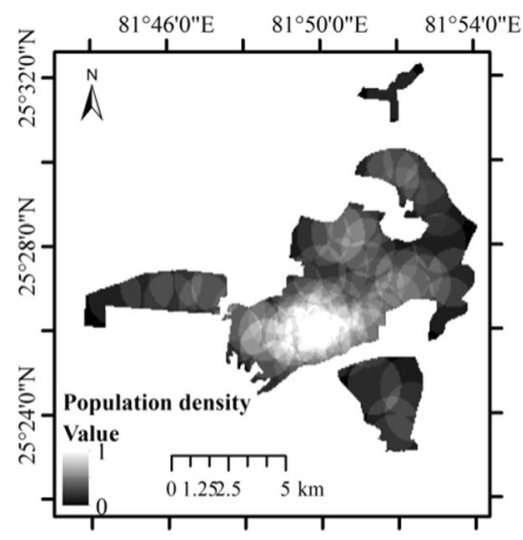

(a) Population density

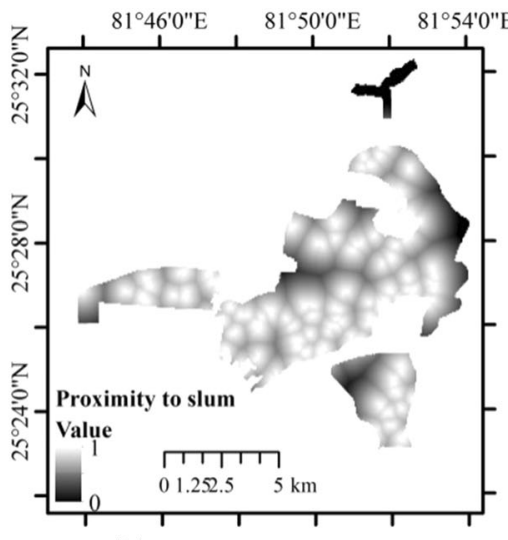

(b) Proximity to slum

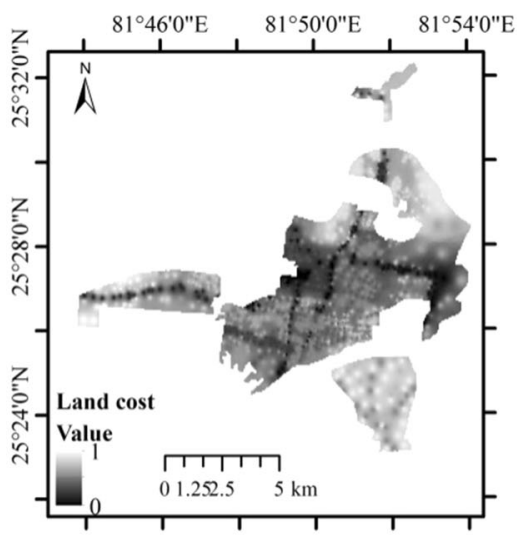

(c) Land cost

Fig. 4 Thematic layer map of socio-economic criteria

for site selection vary in different literature. Table 3 lists all the criteria along with their brief descriptions and the authors who evaluate them in their studies. A total of eleven criteria have been identified for this research. Population density, land cost, accessibility (proximity to road and railway), and possibility of extension have been selected by several researchers. However, air pollution, green area and unhealthy industry norms have also been pointed out as important criteria by some researchers. In very few researches, slope and urban slum population are considered for hospital site selection. These are included in this research as the role of these criteria was found to be very important for the selected study area.
All these criteria are aggregated hierarchically at two levels: main-criteria and sub-criteria. The hierarchical structure of all eleven criteria is shown in Fig. 3. All eleven criteria are grouped into three main criteria viz., socio-economic, geographical and environmental. The socio-economic criterion considers the social and economic factors that are related to human health. Geographical criterion examines access to health facilities. The environmental criterion helps in locating the places where less pollution and more vegetation is around the hospital. 


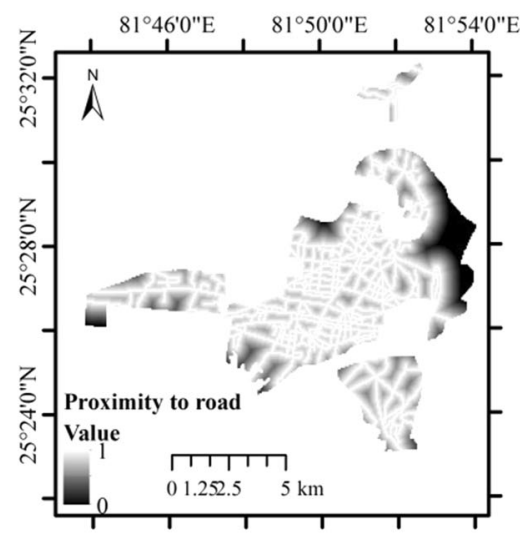

(a) Proximity to road

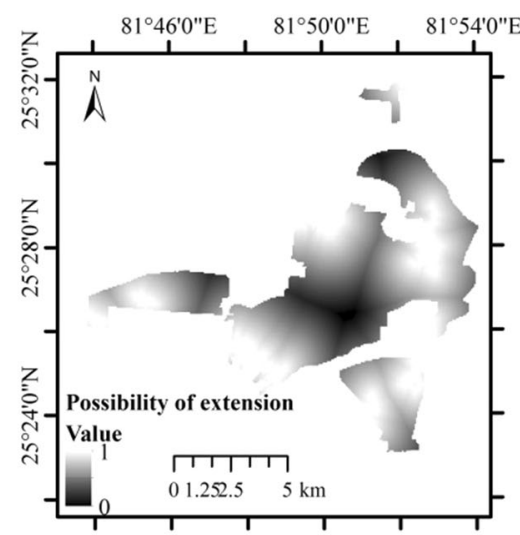

(d) Possibility of extension

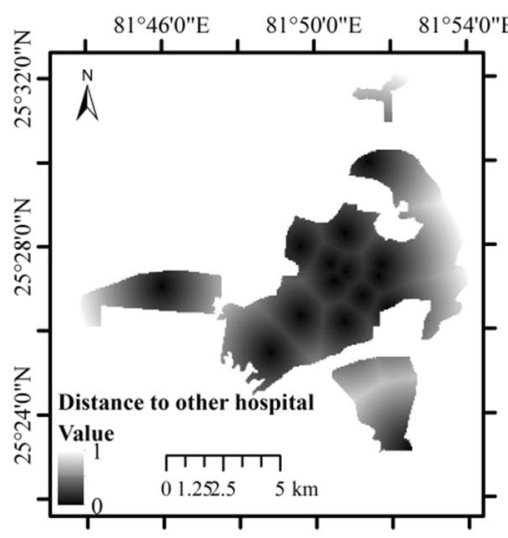

(b) Distance to other hospital

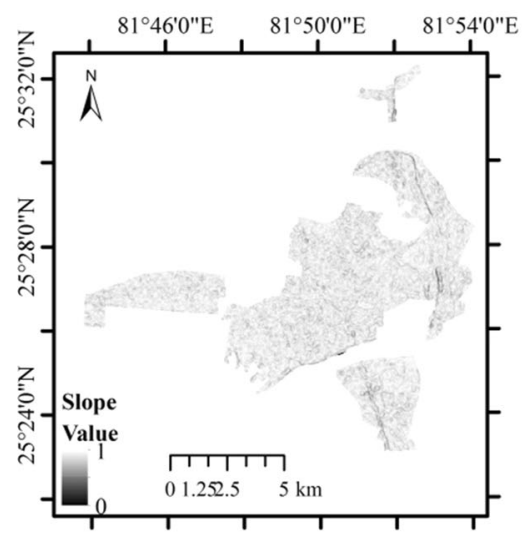

(e) Slope

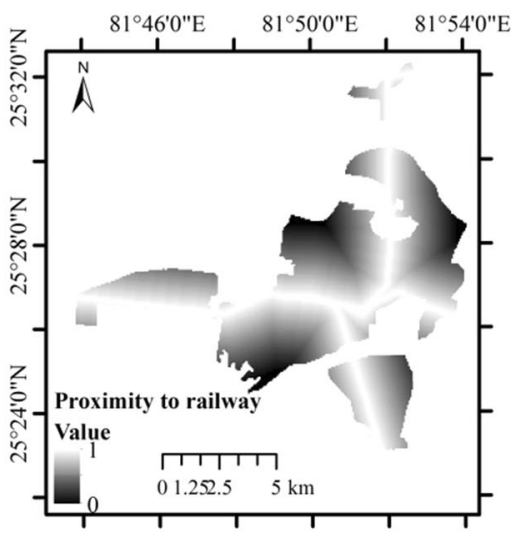

(c) Proximity to railway

Fig. 5 Thematic layer map of geographical criteria

Generation of thematic layers

Spatially referenced criterion provides more detail and visual information that helps decision-makers to make decisions effectively and quickly. This step analyzes the spatial extent of each criterion. It aggregates different geospatial layers to create suitability maps. As different forms of criterion data such as satellite images, topographic maps and field data are collected, different GIS operations such as euclidean distance, slope, interpolation, etc., are needed to create the thematic layer of each criterion. Table 4 presents all the criteria for creating thematic layers with their sources and spatial operations performed on them.

Since most of the data used in this study are in vector format, they need to be converted to raster format. The Raster Calculator and Reclassify GIS tools are used to perform this conversion. This process helps in extracting useful information from the converted file. Here, to maintain the integrity of the measurement, the ranges defined in the thematic layer are normalized in a scale from 0 to 1 . Pixel value 1 denotes the most suitable area for hospital sites and is indicated by white color on the map. The pixel value 0 depicts an area unsuitable for hospital sites and is shown by black color on the map. This helps experts to make critical comparisons among each criterion and to rank the identified alternative sites. The construction of normalized thematic layer maps of each criterion corresponding to all sub-criteria is described below.

\section{Thematic layer map of socio-economic criteria}

The thematic map of socio-economic criteria is shown in Fig. 4.

Population density Population density should be examined to determine population distribution around 


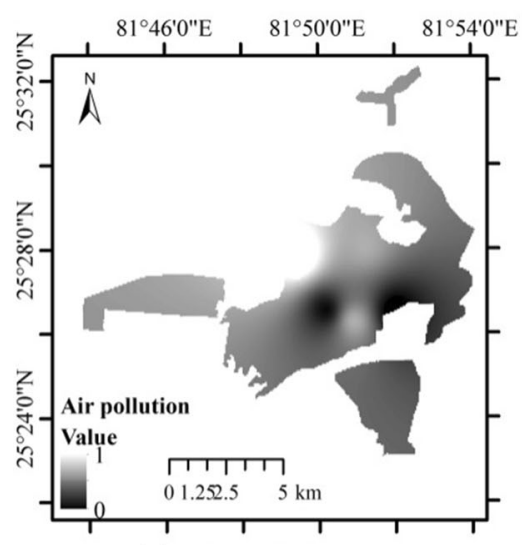

(a) Air pollution

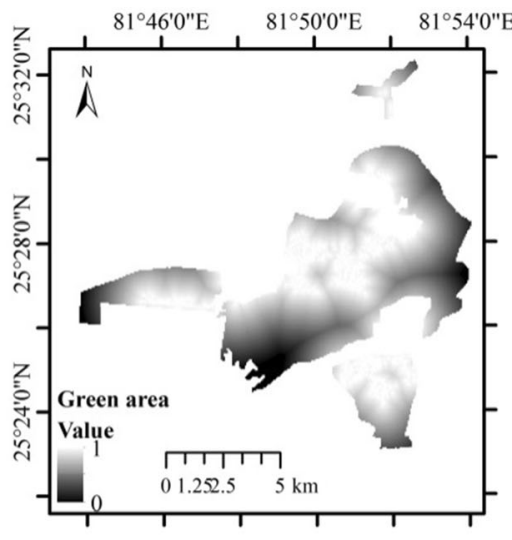

(b) Green area

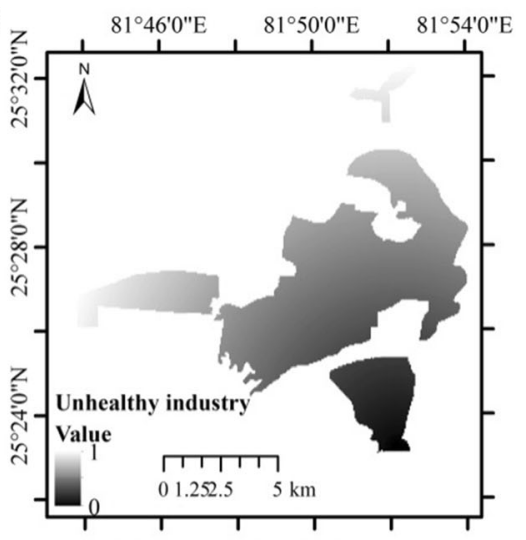

(c) Unhealthy industry

Fig. 6 Thematic layer map of environmental criteria

the city. Hospitals should be located in such a way that more and more population gets the benefit of health services at the nearest possible location. Figure $4 \mathrm{a}$ shows the population density criteria map. In this map, higher population density wards are given a higher score than the wards with lower population density.

Proximity to slum area The slum area is recognized as a highly populated area located in deteriorating infrastructure. There is a high need for health services in the slum and fringe areas as health and sanitation conditions in these areas are generally poor. Figure $4 b$ represents the slum area map where higher scores are given to the slum areas.

Land cost The value of land is an essential parameter in deciding the location of hospital sites. It somehow directly reflected the cost of health care services. The land cost map is shown in Fig. 4c. Higher score is given to the land with lower cost as it is economical to build new hospitals over there.

\section{Thematic layer map of geographical criteria}

The thematic map of geographical criteria is shown in Fig. 5.

Proximity to road Effective transport facilities in terms of access positively affect hospital sites. It benefits those who were in need of health services. It is important to build a new hospital near the streets. In view of this, a high priority has been given to nearby road areas. Figure 5a shows the proximity to road map where higher priority is given to the pixels near to the roads.

Distance to other hospital It is important to assess the availability of existing hospitals. New hospitals should be constructed from existing hospitals so that health services are well distributed around the city. Distance to other hospital map is shown in Fig. 5b in which higher priority is assigned to the area away from the existing hospitals.

Proximity to railway This is another important criterion for the selection of a hospital site. People living away from urban areas sometimes travel via railways. Due to this, the area near the railway is given more priority than the area away from the railway. The proximity to railway map is shown in Fig. 5c.

Possibility of extension Since most of the land within the city is already occupied, it is difficult to acquire land within the city to build a new hospital or to expand an existing one. Keeping this criterion in mind, the open area is given a higher priority than the built-up area. Figure $5 \mathrm{~d}$ shows the possibility of extension map.

Slope The slope of the land may contribute to checking the site of the hospital. Flat or low slope areas are better for building a hospital. Figure 5e shows the slope map, where higher scores are given to the lower slope areas. 
Table 5 Normalized weight of main and sub-criteria

\begin{tabular}{|c|c|c|c|c|c|c|c|c|c|}
\hline \multirow[t]{3}{*}{ Criteria } & \multicolumn{3}{|l|}{ AHP } & \multicolumn{6}{|l|}{ FAHP } \\
\hline & \multirow[t]{2}{*}{ Local weights } & \multirow[t]{2}{*}{ Global weights } & \multirow[t]{2}{*}{ Ranking } & \multicolumn{3}{|c|}{ Fuzzy synthetic extent } & \multirow[t]{2}{*}{ Local weights } & \multirow[t]{2}{*}{ Global weights } & \multirow[t]{2}{*}{ Ranking } \\
\hline & & & & Lower & Middle & Upper & & & \\
\hline $\mathrm{C} 1$ & 0.300 & & & 0.183 & 0.301 & 0.479 & 0.289 & & \\
\hline $\mathrm{C} 2$ & 0.419 & & & 0.281 & 0.419 & 0.602 & 0.461 & & \\
\hline $\mathrm{C} 3$ & 0.281 & & & 0.192 & 0.280 & 0.443 & 0.249 & & \\
\hline \multicolumn{10}{|c|}{ Sub-criteria } \\
\hline C11 & 0.535 & 0.161 & 1 & 0.241 & 0.521 & 1.031 & 0.530 & 0.153 & 3 \\
\hline $\mathrm{C} 12$ & 0.288 & 0.086 & 6 & 0.150 & 0.308 & 0.629 & 0.342 & 0.099 & 5 \\
\hline C13 & 0.177 & 0.053 & 9 & 0.105 & 0.170 & 0.353 & 0.128 & 0.037 & 8 \\
\hline $\mathrm{C} 21$ & 0.306 & 0.128 & 3 & 0.152 & 0.299 & 0.569 & 0.369 & 0.170 & 2 \\
\hline $\mathrm{C} 22$ & 0.336 & 0.141 & 2 & 0.169 & 0.328 & 0.606 & 0.396 & 0.182 & 1 \\
\hline $\mathrm{C} 23$ & 0.156 & 0.065 & 7 & 0.103 & 0.183 & 0.332 & 0.209 & 0.097 & 6 \\
\hline $\mathrm{C} 24$ & 0.101 & 0.042 & 10 & 0.055 & 0.089 & 0.174 & 0.009 & 0.004 & 11 \\
\hline $\mathrm{C} 25$ & 0.101 & 0.042 & 11 & 0.059 & 0.101 & 0.179 & 0.018 & 0.008 & 10 \\
\hline C31 & 0.438 & 0.123 & 4 & 0.268 & 0.459 & 0.741 & 0.534 & 0.133 & 4 \\
\hline C 32 & 0.349 & 0.098 & 5 & 0.216 & 0.329 & 0.504 & 0.344 & 0.086 & 7 \\
\hline C33 & 0.213 & 0.060 & 8 & 0.147 & 0.213 & 0.340 & 0.121 & 0.030 & 9 \\
\hline
\end{tabular}

\section{Thematic layer map of environmental criteria}

The thematic map of environmental criteria is shown in Fig. 6.
Air pollution It is very important to consider air pollution for the selection of a hospital site because it exerts extreme influence around the place in which people live and the hospital is located. If the air pollution around the hospital is high, it will affect the health of patients. Therefore, a lower priority level is

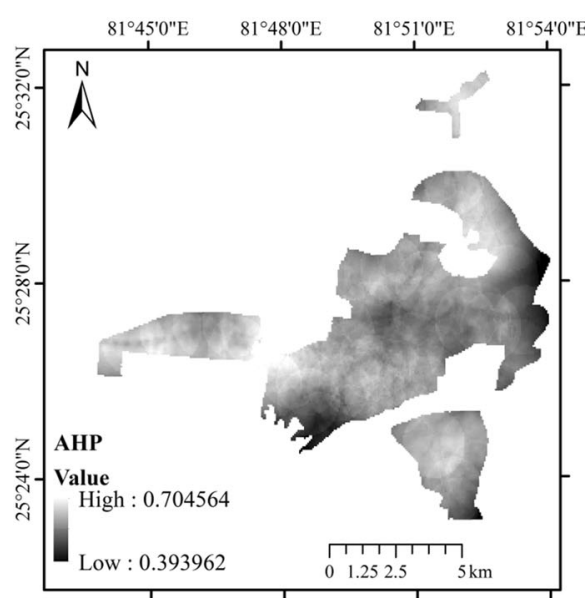

(a)

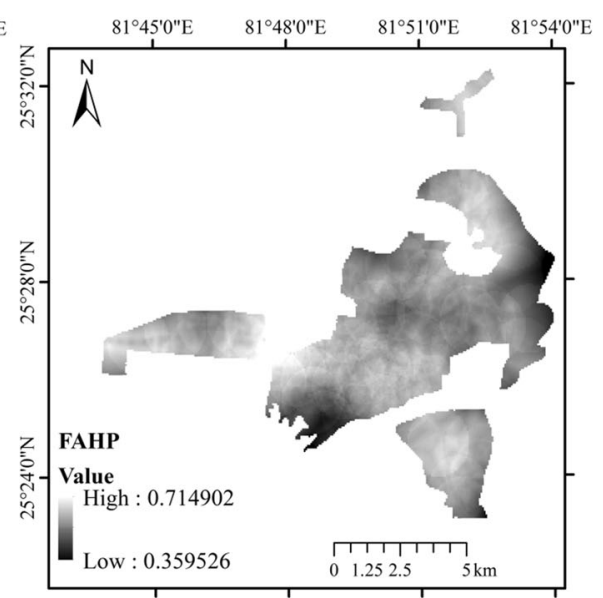

(b)

Fig. 7 Final suitability map of hospital site selection for the Prayagraj city a normalized suitability map of AHP b normalized suitability map of FAHP 
given to the area where the air quality index is higher. Figure 6a represents the air pollution map of the study area.

Green area Surrounding of the hospital plays a crucial role in providing effective healthcare services to the patients. Green area must be present at the hospital sites. Due to this, a higher priority is given to the location near to the green area. Figure $6 b$ represents the green area map of the study area.

Unhealthy industry The industrial sector negatively affects hospital patients due to various types of pollutants, such as wastewater, disposals and hazardous waste. To minimize its impact, the new hospital should be located away from the industrial area. Figure $6 \mathrm{c}$ represents the unhealthy industry map of the study area.

\section{Criteria weights using AHP \& FAHP}

In this step, criteria weights are calculated based on the above definition of AHP and FAHP. For this purpose, expert opinions are considered to assign the weight using the scale given in Tables 1 and 2. To determine the relative importance of each criterion, the opinions of experts are obtained in linguistic terms. It is further transformed and evaluated on a nine-point scale for both AHP and FAHP (Tables 1, 2). In this study, experts from hospital planning authority are taken for their judgment for the site selection of the hospital. The final score of the relative weight is calculated by applying the geometric mean to the expert judgments. The geometric mean method was given by Saaty (1990) and Dyer and Forman (1992) to integrate individual judgments. This will help to generate the PCM for criteria and sub-criteria. After this, the weight is calculated by AHP and FAHP methods. Finally, the overall normalized weight of each subcriterion is calculated by multiplying the individual weight of sub-criteria with the weight of the corresponding criteria (Chang, 1996). Table 5 shows the calculated priority weights and ranking of each subcriteria in AHP and FAHP.

\section{GIS-based MCDA approach}

This step involves GIS-based MCDA analysis to obtain the final suitability map. This is done by implementing a weighted linear combination (WLC) operation. In this operation, more than one attributes or criteria along with its weight are taken into consideration. Each criterion is transformed into a GIS layer and described by its pixel values. The overall suitability map is generated by using Eq. 12 . This formula evaluates the suitability of each pixel based on standardized score and normalized weight.

$$
A_{j}=\sum X_{i} * W_{i}, \text { with } \sum W_{i}=1
$$

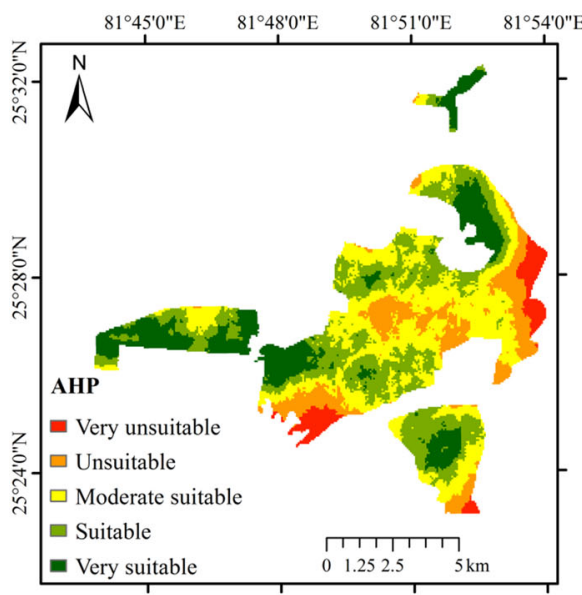

(a)

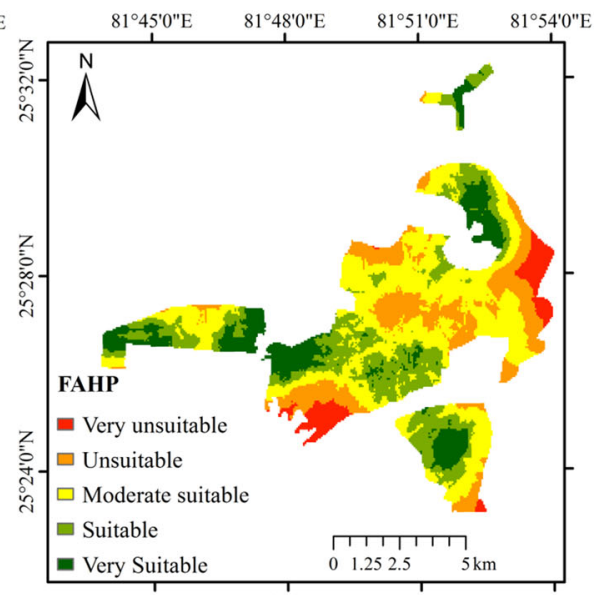

(b)

Fig. 8 Classified suitability map of hospital site selection for the Prayagraj city a classified suitability map of AHP b classified suitability map of FAHP 
Table 6 Comparison of suitability area calculated by AHP and FAHP

\begin{tabular}{lll}
\hline Suitability category for opening new hospital & Area by AHP $\left(\right.$ in $\left.\mathrm{km}^{2}\right)$ & Area by FAHP $\left(\right.$ in $\left.\mathrm{km}^{2}\right)$ \\
\hline Very suitable & 13.83 & 10.55 \\
Suitable & 21.10 & 16.83 \\
Moderate suitable & 24.37 & 28.04 \\
Unsuitable & 10.50 & 13.90 \\
Very unsuitable & 3.81 & 4.22 \\
\hline
\end{tabular}

where $A_{j}$ represents the alternatives score of jth pixel in the final suitability map, $X_{i}$ represents the standardized score of ith criterion, and $\mathrm{W}_{\mathrm{i}}$ represents the normalized weight of ith criterion.

The resulting hospital site suitability maps generated via WLC method are shown in Fig. 7. Here, each criterion GIS layer is multiplied by AHP and FAHP weight separately to generate the corresponding hospital site suitability maps. Raster calculator is used to generate the final hospital site suitability maps for the study area. Figure $7 \mathrm{a}$ and $\mathrm{b}$ shows the normalized suitability map generated from AHP and FAHP, respectively.

To analyze the spatial pattern and distribution of the most appropriate location for the hospital, the normalized maps are classified into five suitability classes: very suitable, suitable, moderately suitable, unsuitable and very unsuitable. This is achieved by applying the natural break (Jenks) classification method to the normalized suitability map. The classified suitability map for AHP and FAHP is shown in Fig. 8a and b, respectively.

Hospital suitability maps generated from AHP and FAHP show some differences in results. It can be seen from Fig. 8a and $b$ that there is a significant difference in a very suitable class. This is due to ranking and weight differences in AHP and FAHP. A quantitative comparison of the differences in the suitability area is also performed, which is summarized in Table 6. This is done by converting all five suitability classes into polygon layers. The results show that $18.78 \%$ of the area in AHP and $14.33 \%$ of area in FAHP are identified as suitable locations for setting up the new hospitals. Higher suitability values are envisioned primarily in an area that is far from the city center as most existing hospitals are located in this area. The total unsuitable and very unsuitable area is about
$19.44 \%$ and $24.62 \%$ of the total area in AHP and FAHP respectively.

\section{Comparative analysis}

A comparison between AHP and FHAP results is made in this section on the basis of three parameters, which are (1) divergence in criteria ranking (2) extent and location of hospital sites and (3) weight change influence on sites ranking in different scenario based on sensitivity analysis.

\section{Criteria ranking}

The one of the critical input in GIS-based MCDA analysis is the ranking of criteria based on the relative importance of each criterion. Here from Table 5, it can be seen that the criteria ranking and weighting results derived by AHP and FAHP are quite different. By criterion weighting, it appears that the relative local weights of each criterion and sub-criterion are the same in AHP and FAHP. However, the global weight ranking differs in both methods. For example, in AHP, population density $(\mathrm{C} 11)$ is ranked as the most important criterion, whereas in FAHP, distance to other hospital (C22) is assigned as the most important criterion. The Possibility of extension (C24) and slope (C25) are given the lowest priority for both AHP and FAHP.

The biggest differences in global weight can be seen for proximity to railway (C23) and unhealthy industry (C33), as they have almost the same impact in AHP while in FAHP method proximity to the railway (C23) has a greater impact than unhealthy industry (C33). This happens because in the AHP method, an exact numerical number is given as a weight by the 
Fig. 9 Alternative hospital sites in the AHP and FAHP

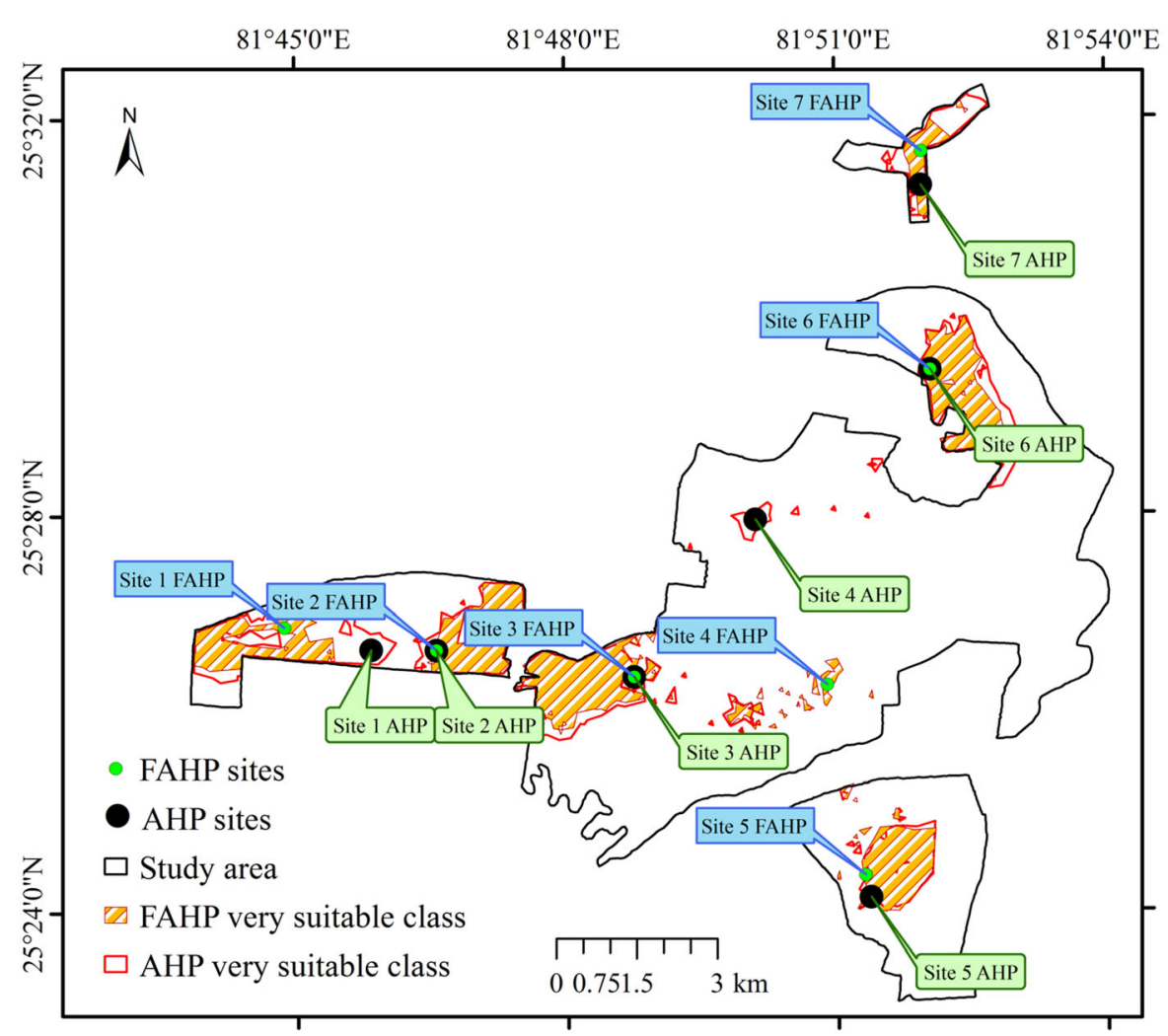

Table 7 Ranking of sites using AHP

\begin{tabular}{lllllllllllllll}
\hline & C11 & C12 & C13 & C21 & C22 & C23 & C24 & C25 & C31 & C32 & C33 & Weight & Rank \\
\hline Site 1 AHP & 0.082 & 0.167 & 0.120 & 0.187 & 0.076 & 0.106 & 0.235 & 0.198 & 0.186 & 0.132 & 0.256 & 0.145 & 2 \\
Site 2 AHP & 0.144 & 0.167 & 0.064 & 0.187 & 0.080 & 0.071 & 0.043 & 0.070 & 0.186 & 0.240 & 0.167 & 0.142 & 5 \\
Site 3 AHP & 0.250 & 0.167 & 0.120 & 0.098 & 0.134 & 0.071 & 0.069 & 0.286 & 0.065 & 0.048 & 0.051 & 0.127 & 6 \\
Site 4 AHP & 0.250 & 0.167 & 0.051 & 0.187 & 0.080 & 0.066 & 0.157 & 0.070 & 0.305 & 0.240 & 0.082 & 0.172 & 1 \\
Site 5 AHP & 0.082 & 0.083 & 0.215 & 0.058 & 0.276 & 0.226 & 0.346 & 0.060 & 0.043 & 0.076 & 0.075 & 0.127 & 7 \\
Site 6 AHP & 0.144 & 0.167 & 0.215 & 0.098 & 0.134 & 0.297 & 0.043 & 0.198 & 0.108 & 0.132 & 0.114 & 0.143 & 4 \\
Site 7 AHP & 0.050 & 0.083 & 0.215 & 0.187 & 0.221 & 0.163 & 0.108 & 0.118 & 0.108 & 0.132 & 0.256 & 0.143 & 3 \\
\hline
\end{tabular}

experts. While at FAHP, experts' decisions are driven by the consideration of triangular fuzzy numbers, which can have a large impact on the final weight of the criteria.

Although this comparison shows differences in AHP and FAHP weights and rankings, it does not recognize the true impact of this difference on the final result. Therefore, the next section is done to see the difference between the outcomes of both methods.
Extent and location of hospital sites

This comparison is done on the basis of alternative sites identified by APH and FAHP method where new hospitals are to be established. Here, the area that falls under the very suitable class is considered for further selection. Along with this, another consideration has also been taken that new hospital sites should be in only those wards which do not have any hospital. The location for the new hospital is identified based on the 
Table 8 Ranking of sites using FAHP

\begin{tabular}{lllllllllllllll}
\hline & C11 & C12 & C13 & C21 & C22 & C23 & C24 & C25 & C31 & C32 & C33 & Weight & Rank \\
\hline Site 1 FAHP & 0.227 & 0.231 & 0.170 & 0.166 & 0.150 & 0.107 & 0.134 & 0.171 & 0.052 & 0.262 & 0.002 & 0.158 & 3 \\
Site 2 FAHP & 0.003 & 0.202 & 0.074 & 0.257 & 0.209 & 0.192 & 0.011 & 0.259 & 0.119 & 0.057 & 0.144 & 0.132 & 6 \\
Site 3 FAHP & 0.234 & 0.030 & 0.170 & 0.307 & 0.106 & 0.107 & 0.229 & 0.066 & 0.176 & 0.120 & 0.069 & 0.136 & 5 \\
Site 4 FAHP & 0.003 & 0.202 & 0.074 & 0.004 & 0.243 & 0.192 & 0.286 & 0.265 & 0.176 & 0.196 & 0.283 & 0.182 & 1 \\
Site 5 FAHP & 0.249 & 0.029 & 0.170 & 0.257 & 0.001 & 0.192 & 0.010 & 0.002 & 0.053 & 0.048 & 0.002 & 0.095 & 7 \\
Site 6 FAHP & 0.101 & 0.278 & 0.170 & 0.005 & 0.243 & 0.019 & 0.318 & 0.066 & 0.176 & 0.120 & 0.283 & 0.139 & 4 \\
Site 7 FAHP & 0.182 & 0.029 & 0.170 & 0.005 & 0.048 & 0.192 & 0.011 & 0.171 & 0.248 & 0.196 & 0.216 & 0.159 & 2 \\
\hline
\end{tabular}

Table 9 Sensitivity analysis result of AHP weights

\begin{tabular}{llllllllllll}
\hline & $\mathrm{C} 11$ & $\mathrm{C} 12$ & $\mathrm{C} 13$ & $\mathrm{C} 21$ & $\mathrm{C} 22$ & $\mathrm{C} 23$ & $\mathrm{C} 24$ & $\mathrm{C} 25$ & $\mathrm{C} 31$ & $\mathrm{C} 32$ & $\mathrm{C} 33$ \\
\hline $50 \%$ & 0.136 & 0.088 & 0.033 & 0.151 & 0.274 & 0.086 & 0.004 & 0.007 & 0.118 & 0.076 & 0.027 \\
$40 \%$ & 0.140 & 0.090 & 0.034 & 0.155 & 0.255 & 0.088 & 0.004 & 0.007 & 0.121 & 0.078 & 0.028 \\
$30 \%$ & 0.143 & 0.092 & 0.035 & 0.159 & 0.237 & 0.090 & 0.004 & 0.008 & 0.124 & 0.080 & 0.028 \\
$20 \%$ & 0.147 & 0.095 & 0.035 & 0.162 & 0.219 & 0.092 & 0.004 & 0.008 & 0.127 & 0.082 & 0.029 \\
$10 \%$ & 0.150 & 0.097 & 0.036 & 0.166 & 0.201 & 0.094 & 0.004 & 0.008 & 0.130 & 0.084 & 0.030 \\
$0 \%$ & 0.153 & 0.099 & 0.037 & 0.170 & 0.182 & 0.097 & 0.004 & 0.008 & 0.133 & 0.086 & 0.030 \\
$-10 \%$ & 0.157 & 0.101 & 0.038 & 0.174 & 0.164 & 0.099 & 0.004 & 0.008 & 0.136 & 0.088 & 0.031 \\
$-20 \%$ & 0.160 & 0.103 & 0.039 & 0.178 & 0.146 & 0.101 & 0.004 & 0.008 & 0.139 & 0.090 & 0.032 \\
$-30 \%$ & 0.164 & 0.106 & 0.040 & 0.181 & 0.128 & 0.103 & 0.004 & 0.009 & 0.142 & 0.092 & 0.032 \\
$-40 \%$ & 0.167 & 0.108 & 0.040 & 0.185 & 0.109 & 0.105 & 0.004 & 0.009 & 0.145 & 0.094 & 0.033 \\
$-50 \%$ & 0.170 & 0.110 & 0.041 & 0.189 & 0.091 & 0.107 & 0.004 & 0.009 & 0.148 & 0.095 & 0.034 \\
\hline
\end{tabular}

\begin{tabular}{llllllllllll}
\hline & $\mathrm{C} 11$ & $\mathrm{C} 12$ & $\mathrm{C} 13$ & $\mathrm{C} 21$ & $\mathrm{C} 22$ & $\mathrm{C} 23$ & $\mathrm{C} 24$ & $\mathrm{C} 25$ & $\mathrm{C} 31$ & $\mathrm{C} 32$ & $\mathrm{C} 33$ \\
\hline $50 \%$ & 0.241 & 0.078 & 0.048 & 0.118 & 0.127 & 0.059 & 0.038 & 0.037 & 0.111 & 0.089 & 0.054 \\
$40 \%$ & 0.225 & 0.080 & 0.049 & 0.120 & 0.130 & 0.060 & 0.039 & 0.038 & 0.114 & 0.091 & 0.055 \\
$30 \%$ & 0.209 & 0.081 & 0.050 & 0.123 & 0.132 & 0.061 & 0.040 & 0.039 & 0.116 & 0.093 & 0.056 \\
$20 \%$ & 0.193 & 0.083 & 0.051 & 0.125 & 0.135 & 0.062 & 0.041 & 0.040 & 0.118 & 0.094 & 0.058 \\
$10 \%$ & 0.177 & 0.085 & 0.052 & 0.128 & 0.138 & 0.063 & 0.042 & 0.041 & 0.121 & 0.096 & 0.059 \\
$0 \%$ & 0.161 & 0.086 & 0.053 & 0.130 & 0.140 & 0.065 & 0.042 & 0.041 & 0.123 & 0.098 & 0.060 \\
$-10 \%$ & 0.144 & 0.088 & 0.054 & 0.133 & 0.143 & 0.066 & 0.043 & 0.042 & 0.125 & 0.100 & 0.061 \\
$-20 \%$ & 0.128 & 0.090 & 0.055 & 0.135 & 0.146 & 0.067 & 0.044 & 0.043 & 0.128 & 0.102 & 0.062 \\
$-30 \%$ & 0.112 & 0.091 & 0.056 & 0.138 & 0.148 & 0.068 & 0.045 & 0.044 & 0.130 & 0.104 & 0.063 \\
$-40 \%$ & 0.096 & 0.093 & 0.057 & 0.140 & 0.151 & 0.070 & 0.046 & 0.044 & 0.133 & 0.106 & 0.065 \\
$-50 \%$ & 0.080 & 0.095 & 0.058 & 0.143 & 0.154 & 0.071 & 0.046 & 0.045 & 0.135 & 0.108 & 0.066 \\
\hline
\end{tabular}




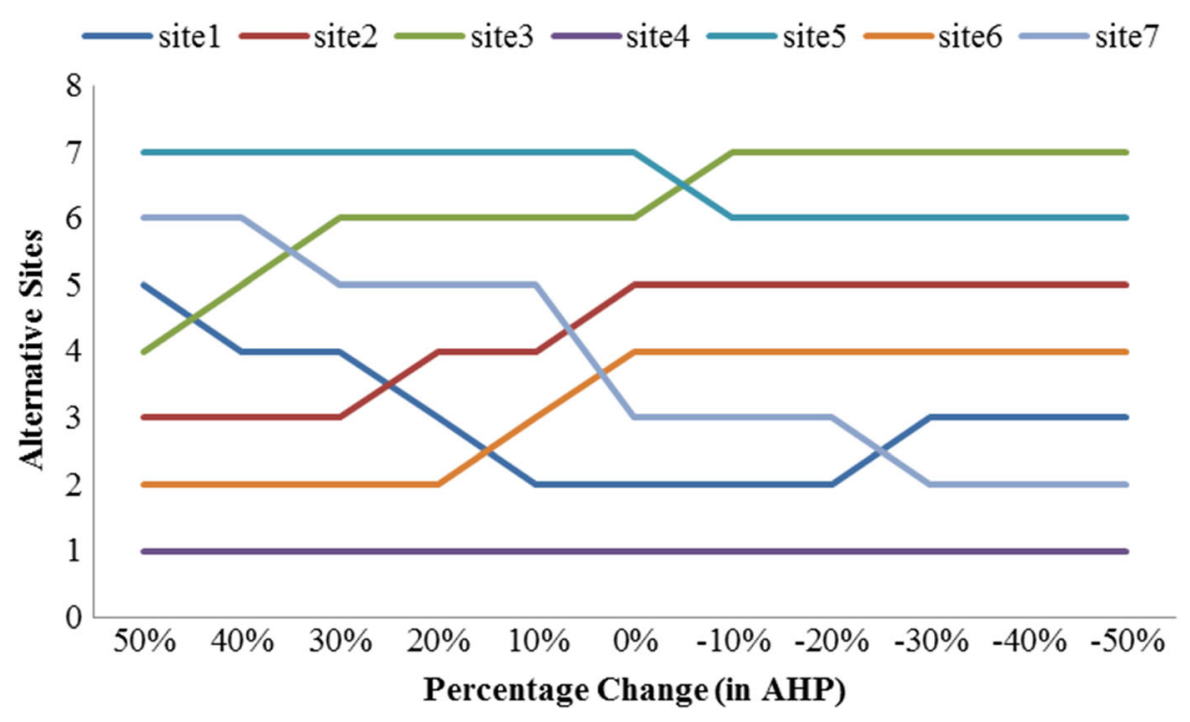

Fig. 10 Impact of sensitivity analysis in the sites determined in AHP sites

Fig. 11 Impact of sensitivity analysis in the sites determined in FAHP sites

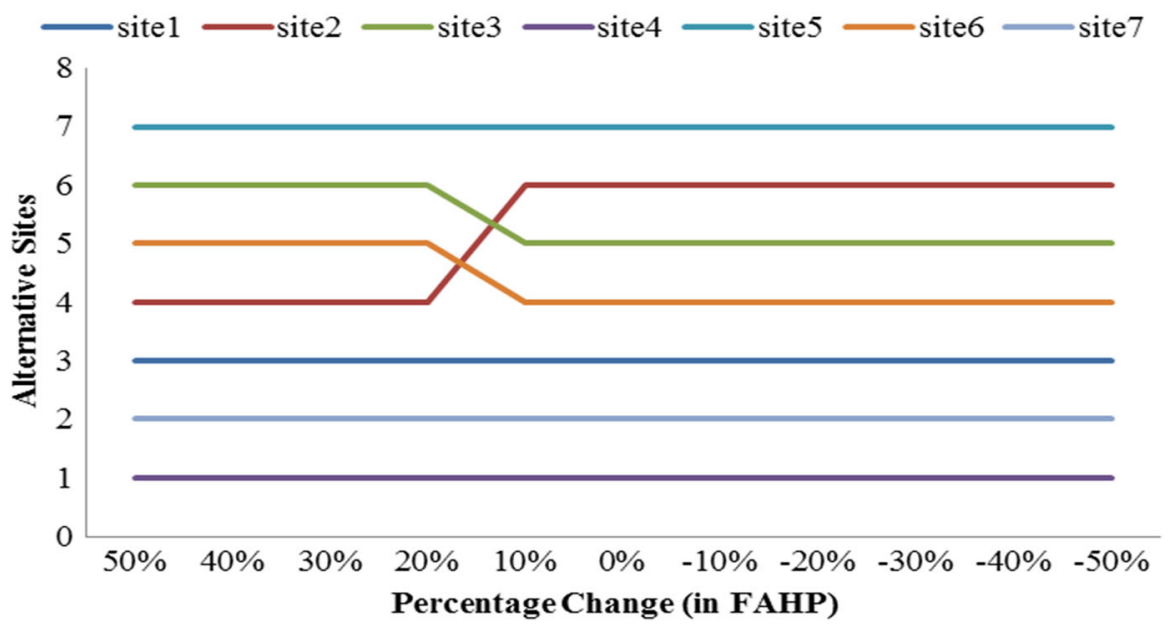

pixel values. A higher pixel value indicates greater adherence to the criterion, thus it is more appropriate than a lower pixel value. Based on the above conditions, seven alternative locations for hospital sites are identified by both methods from a very suitable class. Very suitable class area with the alternative sites by AHP and FAHP is shown in Fig. 9. Here, it can be seen that three of those sites are identified at the same location by both methods.

Next, the spatial distribution and ranking order of these identified alternative sites is calculated and then compared in both methods. For this purpose, weight order of each site with respect to each criterion is calculated by AHP and FAHP methods. Here, criteria weights and PCM of each alternative site in regard to each criterion are taken part to calculate the final weight and ranking of each site. The overall weight and ranking of each criterion by both methods are shown in Tables 7 and 8, respectively. This analysis shows that the ranking order of sites differed slightly in both methods. For example, Site 1, Site 2, Site 3 and Site 7 are located in the same ward, but the ranking order differs in both methods. However, Site 5 and Site 6 are not only located in one place, but they ranked in the same order by both methods. Although Site 4 option from the AHP and FAHP is located in separate 
wards, this analysis ranked it as the most appropriate location for the hospital site.

\section{Sensitivity analysis}

Sensitivity analysis is used to test the reliability and robustness of alternative sites in various models. In other words, it identifies the sensitivity of alternatives to the criteria weight changes. To examine this analysis, the weight of one criterion is changed while keeping the others to the same. In this way different combinations of weights are prepared. Experiments are then conducted to evaluate the impact of the weight variation on the output. High degree of change shows high sensitivity in output.

To perform the sensitivity analysis, weight $\left(\mathrm{w}_{\mathrm{i}}\right)$ of each criterion is altered at a certain percentage change (PC). Weight is calculated by the following equations:

$w_{i}=w_{i 0} \pm w_{i 0} \times \mathrm{PC}$

$w_{j}=\left(1-w_{i}\right) \times \frac{w_{j 0}}{\left(1-w_{i 0}\right)}$

where $\mathrm{w}_{\mathrm{i} 0}$ is the weight of the main affecting criterion. $\mathrm{w}_{\mathrm{i}}$ and $\mathrm{w}_{\mathrm{j}}$ is the new weight value assigned to the ith and jth criterion. $w_{i 0}$ and $w_{j 0}$ are the weights of criterion $i$ and $j$, which are used as an input at base run.

To apply criteria weight change analysis, weight deviation range from +50 to $-50 \%$ with the percent change of $10 \%$ is applied in this study. To do the fair comparison between AHP and FAHP results, the sensitivity analysis is done separately for both methods. Due to having highest weight among other criteria, population density and distance to other hospital criterion is selected as the main affecting criterion for AHP and FAHP, respectively. Criteria weight change according to AHP and FAHP is shown in Tables 9 and 10, respectively.

After generating the criteria weight changes, their impact in the overall ranking is analyzed. For this, overall weight of sites with respect to each criteria weight change is calculated using the weighted operation. The results of ranking order of sites in AHP and FAHP are shown in Figs. 10 and 11, respectively. The AHP result shows a continuous variation in the order of site ranking in respect to criteria weight change. In FAHP, the order of site ranking varies only between +10 and $+20 \%$ criterion weight while other weight deviations have no effect on site ranking. From the results, it can be seen that Site 4 is identified as the most suitable location for hospital siting both ways. Thus the impact of criteria weight change in the FAHP sites is nearly negligible. The sensitivity analysis results suggest that the FAHP site ranking is more tolerant for the criteria weight change than the AHP ranking.

\section{Conclusions}

The site selection like problems that have multiple conflicting criteria requires MCDA based decision making. AHP can be used for this purpose as it can handle both qualitative and quantitative parameters. It integrates expert opinion, specialist experience and public feedback to assign the weights to these criteria. Sometimes, FAHP is used instead of AHP to incorporate the vagueness of human thinking. FAHP use the fuzzy number instead of the crisp number in the weight assignment. In this research work, a four-step methodology is proposed for hospital site selection along with the comparative analysis of AHP and FAHP. In the first step, the parameters are picked under three broad categories, viz, socio-economic criteria, geographical criteria and environmental criteria. Eleven sub-criteria are subsequently identified under them: population density, proximity to slum, land cost, proximity to road, distance to other hospitals, proximity to railway, possibility of extension, slope, air pollution, green area and unhealthy industry. After the screening and selecting of criteria and sub-criteria, thematic layers are generated and weight is assigned to them on a ninepoint scale. In FAHP, the extend analysis method is used to calculate the crisp weights. Finally, suitability maps are generated using both methods. Total of nine sites are identified in each of the methods where hospitals can be established.

The AHP and FAHP are compared based on the criterion ranking, location of sites and sensitivity analysis. It shows that these methods' difference in the criterion weight assignment is ultimately reflected in the respective criterion ranking. The criterion weight change has an impact on the final suitability map which varies between these two methods. For example, in AHP, the population density criterion greatly impacts the final suitability map, whereas in FAHP, it is the distance to other hospitals. The results of both methods on final suitability indicate high variance in 
the ranking of their respective alternative locations. The result of sensitivity analysis shows high differences in the outcomes of both methods. This difference is not only due to distinct sets of alternative sites from AHP and FAHP but also due to the spatial extent of site location. The sensitivity analysis results show that the FAHP site ranking is more tolerant of the criteria weight change than the AHP ranking.

This study has shown the use of AHP and FAHP in the complex decision making of hospital site selection. It could help the local administrators in the handling of the emerging health threats in a more efficient manner. The solution can reduce the widening gap between the patients and the availability of health infrastructure in present COVID-19 like situations. In the future, this study can be further enhanced by including more demographic parameters of that location like age, medical insurance, education and employment.

Funding No funding received for this study.

\section{Declarations}

Conflict of interest The authors declare that they have no conflict of interest.

Human or animal rights The research does not involve human participants or animals.

\section{References}

Aggarwal, R., \& Singh, S. (2013). AHP and extent fuzzy AHP approach for prioritization of performance measurement attributes. Industrial \& Manufacturing Engineering, 7(1), 6-11. https://doi.org/10.5281/zenodo.1082718

Ahmed, A. H., Mahmoud, H., \& Aly, A. M. M. (2016). Site suitability evaluation for sustainable distribution of hospital using spatial information technologies and AHP: A case study of upper Egypt, Aswan City. Journal of Geographic Information System, 8(5), 578-594. https://doi. org/10.4236/jgis.2016.85048

Aksoy, E., \& San, B. T. (2019). Geographical information systems (GIS) and multi-criteria decision analysis (MCDA) integration for sustainable landfill site selection considering dynamic data source. Bulletin of Engineering Geology and the Environment, 78(2), 779-791. https://doi. org/10.1007/s10064-017-1135-Z

Ayağ, Z. (2014). A fuzzy analytic hierarchy process tool to evaluate computer-aided manufacturing software alternatives. Turkish Journal of Fuzzy Systems, 5(2), 114-127.

Aydi, A., Abichou, T., Nasr, I. H., Louati, M., \& Zairi, M. (2016). Assessment of land suitability for olive mill wastewater disposal site selection by integrating fuzzy logic, AHP, and WLC in a GIS. Environmental Monitoring and Assessment, 188(1), 1-13. https://doi.org/10.1007/ s10661-015-5076-3

Buckley, J. J. (1985). Fuzzy hierarchical analysis. Fuzzy Sets and Systems, 17(3), 233-247. https://doi.org/10.1016/ 0165-0114(85)90090-9

Caligiuri, P., De Cieri, H., Minbaeva, D., Verbeke, A., \& Zimmermann, A. (2020). International HRM insights for navigating the COVID-19 pandemic: Implications for future research and practice. Journal of International Business Studies, 51(5), 697-713. https://doi.org/10.1057/ s41267-020-00335-9

Çetinkaya, C., Kabak, M., Erbaş, M., \& Özceylan, E. (2018). Evaluation of ecotourism sites: A GIS-based multi-criteria decision analysis. Kybernetes, 47(8), 1664-1686. https:// doi.org/10.1108/K-10-2017-0392

Çetinkaya, C., Özceylan, E., Erbaş, M., \& Kabak, M. (2016). GIS-based fuzzy MCDA approach for siting refugee camp: A case study for southeastern Turkey. International Journal of Disaster Risk Reduction, 18, 218-231. https://doi. org/10.1016/j.ijdrr.2016.07.004

Chan, H. K., Wang, X., White, G. R. T., \& Yip, N. (2013). An extended fuzzy-AHP approach for the evaluation of green product designs. IEEE Transactions on Engineering Management, 60(2), 327-339. https://doi.org/10.1109/ TEM.2012.2196704

Chang, D. Y. (1996). Applications of the extent analysis method on fuzzy AHP. European Journal of Operational Research, 95(3), 649-655. https://doi.org/10.1016/03772217(95)00300-2

Chaudhary, P., Chhetri, S. K., Joshi, K. M., Shrestha, B. M., \& Kayastha, P. (2016). Application of an analytic hierarchy process (AHP) in the GIS interface for suitable fire site selection: A case study from Kathmandu Metropolitan City Nepal. Socio-Economic Planning Sciences, 53, 60-71. https://doi.org/10.1016/j.seps.2015.10.001

Daskin, M. S., \& Dean, L. K. (2004). Location of health care facilities. In M. L. Brandeau, F. Sainfort, \& W. P. Pierskalla (Eds.), Operations research and health care: $A$ hand- book of methods and applications (pp. 43-76). Kluwer:Springer. https://doi.org/10.1007/1-4020-8066-2_ 3

Dehe, B., \& Bamford, D. (2015). Development, test and comparison of two multiple criteria decision analysis (MCDA) models: A case of healthcare infrastructure location. Expert Systems with Applications, 42(19), 6717-6727. https://doi. org/10.1016/j.eswa.2015.04.059

Dell'Ovo, M., Capolongo, S., \& Oppio, A. (2018). Combining spatial analysis with MCDA for the siting of healthcare facilities. Land Use Policy, 76, 634-644. https://doi.org/10. 1016/j.landusepol.2018.02.044

Demirel, T., Demirel, N. C., \& Kahraman, C. (2008). Fuzzy analytic hierarchy process and its application. In $\mathrm{C}$. Kahraman (Ed.), Fuzzy multi-criteria decision making. Springer optimization and its applications (1st ed., pp. 53-83). Springer. https://doi.org/10.1007/978-0-38776813-7_3

Ding, Z., Niu, J., Liu, S., Wu, H., \& Zuo, J. (2020). An approach integrating geographic information system and building information modelling to assess the building health of commercial buildings. Journal of Cleaner Production. https://doi.org/10.1016/j.jclepro.2020.120532 
Dyer, R. F., \& Forman, E. H. (1992). Group decision support with the analytic hierarchy process. Decision Support Systems, 8(2), 99-124. https://doi.org/10.1016/01679236(92)90003-8

Erbaş, M., Kabak, M., Özceylan, E., \& Çetinkaya, C. (2018). Optimal siting of electric vehicle charging stations: A GISbased fuzzy multi-criteria decision analysis. Energy, 163, 1017-1031. https://doi.org/10.1016/j.energy.2018.08.140

Feizizadeh, B., Shadman Roodposhti, M., Jankowski, P., \& Blaschke, T. (2014). A GIS-based extended fuzzy multicriteria evaluation for landslide susceptibility mapping. Computers and Geosciences, 73, 208-221. https://doi.org/ 10.1016/j.cageo.2014.08.001

Garni, H. Z. A., \& Awasthi, A. (2017). Solar PV power plant site selection using a GIS-AHP based approach with application in Saudi Arabia. Applied Energy, 206(September), 1225-1240. https://doi.org/10.1016/j.apenergy.2017.10. 024

Guler, D., \& Yomralioglu, T. (2020). Suitable location selection for the electric vehicle fast charging station with AHP and fuzzy AHP methods using GIS. Annals of GIS, 26(2), 169-189. https://doi.org/10.1080/19475683.2020.1737226

Hariz, H. A., Dönmez, C. Ç., \& Sennaroglu, B. (2017). Siting of a central healthcare waste incinerator using GIS-based multi-criteria decision analysis. Journal of Cleaner Production, 166, 1031-1042. https://doi.org/10.1016/j.jclepro. 2017.08.091

Jabaris, S. S. L., \& Ananthalakshmi, V. (2021). The current situation of COVID-19 in India. Brain, Behavior, \& Immunity—Health, . https://doi.org/10.1016/j.bbih.2021. 100200

Kahraman, C., Kutlu Gundogdu, F., Cevik Onar, S., \& Oztaysi, B. (2019). Hospital location selection using spherical fuzzy TOPSIS. In Proceedings of the 2019 conference of the international fuzzy systems association and the european society for fuzzy logic and technology (EUSFLAT 2019) (pp. 77-82). Paris, France: Atlantis Press. https://doi.org/ 10.2991/eusflat-19.2019.12

Kim, J., Senaratna, D., Ruza, J., Kam, C., \& Ng, S. (2015). Feasibility Study on an evidence-based decision-support system for hospital site selection for an aging population. Sustainability, 7(3), 2730-2744. https://doi.org/10.3390/ su7032730

Kumar, P., Singh, R. K., \& Sinha, P. (2016). Optimal site selection for a hospital using a fuzzy extended ELECTRE approach. Journal of Management Analytics, 3(2), 115-135. https://doi.org/10.1080/23270012.2016.1152170

Longaray, A., Ensslin, L., Ensslin, S., Alves, G., Dutra, A., \& Munhoz, P. (2018). Using MCDA to evaluate the performance of the logistics process in public hospitals: The case of a Brazilian teaching hospital. International Transactions in Operational Research, 25(1), 133-156. https://doi.org/ 10.1111/itor.12387

Maguire, D. J. (1991). An overview and definition of GIS. In D. J. Maguire, M. F. Goodchild, \& D. W. Rhind (Eds.), geographical information systems: Principles and applications (pp. 9-20). Wiley.

Malczewski, J., \& Rinner, C. (2015). Multicriteria decision analysis in geographic information science. Springer. https://doi.org/10.1007/978-3-540-74757-4
Mateus, R., Ferreira, J. A., \& Carreira, J. (2008). Multicriteria decision analysis (MCDA): Central porto high-speed railway station. European Journal of Operational Research, 187(1), 1-18. https://doi.org/10.1016/j.ejor.2007.04.006

Miç, P., \& Antmen, Z. F. (2019). A healthcare facility location selection problem with fuzzy TOPSIS method for a regional hospital. European Journal of Science and Technology, 16, 750-757. https://doi.org/10.31590/ejosat. 584217

Mikhailov, L. (2003). Deriving priorities from fuzzy pairwise comparison judgements. Fuzzy Sets and Systems, 134(3), 365-385. https://doi.org/10.1016/S0165-0114(02)00383-4

Mishra, S., Sahu, P. K., Sarkar, A. K., Mehran, B., \& Sharma, S. (2019). Geo-spatial site suitability analysis for development of health care units in rural India: Effects on habitation accessibility, facility utilization and zonal equity in facility distribution. Journal of Transport Geography, 78, 135-149. https://doi.org/10.1016/j.jtrangeo.2019.05.017

Murad, A. A. (2007). Creating a GIS application for health services at Jeddah city. Computers in Biology and Medicine, 37(6), 879-889. https://doi.org/10.1016/j. compbiomed.2006.09.006

Murat, Y. S., Arslan, T., Cakici, Z., \& Akçam, C. (2015). Analytical hierarchy process (AHP) based decision support system for urban intersections in transportation planning. In L. Johnston (Ed.), Using decision support systems for transportation planning efficiency (pp. 203-222). IGI Global Publishing. https://doi.org/10.4018/978-1-46668648-9.ch008

Nyimbili, P. H., \& Erden, T. (2020). GIS-based fuzzy multicriteria approach for optimal site selection of fire stations in Istanbul Turkey. Socio-Economic Planning Sciences. https://doi.org/10.1016/j.seps.2020.100860

Oppio, A., Buffoli, M., Ovo, M. D., \& Capolongo, S. (2016). Addressing decisions about new hospitals'siting: A multidimensional evaluation approach. Annali Dell'istituto Superiore Di Sanità, 52(1), 78-87. https://doi.org/10.4415/ ANN

Pantzartzis, E., Edum-Fotwe, F. T., \& Price, A. D. F. (2017). Sustainable healthcare facilities: Reconciling bed capacity and local needs. International Journal of Sustainable Built Environment, 6(1), 54-68. https://doi.org/10.1016/j.ijsbe. 2017.01.003

Prasertsri, N., \& Sangpradid, S. (2020). Parking Site Selection for Light Rail Stations in Muaeng District, Khon Kaen Thailand. Symmetry, 12(6), 1055. https://doi.org/10.3390/ sym 12061055

Rahimi, F., Goli, A., \& Rezaee, R. (2017). Hospital locationallocation in Shiraz using geographical information system (GIS). Shiraz E Medical Journal. https://doi.org/10.5812/ semj.57572

Rahmat, Z. G., Niri, M. V., Alavi, N., Goudarzi, G., Babaei, A. A., Baboli, Z., \& Hosseinzadeh, M. (2017). Landfill site selection using GIS and AHP: A case study: Behbahan Iran. KSCE Journal of Civil Engineering, 21(1), 111-118. https://doi.org/10.1007/s12205-016-0296-9

Rajak, M., \& Shaw, K. (2019). Evaluation and selection of mobile health (mHealth) applications using AHP and fuzzy TOPSIS. Technology in Society, 59, 101186. https://doi. org/10.1016/j.techsoc.2019.101186 
Rajasekhar, M., Sudarsana Raju, G., Sreenivasulu, Y., \& Siddi Raju, R. (2019). Delineation of groundwater potential zones in semi-arid region of Jilledubanderu river basin, Anantapur District, Andhra Pradesh, India using fuzzy logic, AHP and integrated fuzzy-AHP approaches. $H y$ droResearch, 2, 97-108. https://doi.org/10.1016/j.hydres. 2019.11.006

Ramani, K. V., Mavalankar, D., Patel, A., \& Mehandiratta, S. (2007). A GIS approach to plan and deliver healthcare services to urban poor. International Journal of Pharmaceutical and Healthcare Marketing, 1(2), 159-173. https:// doi.org/10.1108/17506120710763004

Reath, J., King, M., Kmet, W., O'Halloran, D., Brooker, R., Aspinall, D., et al. (2019). Experiences of primary healthcare professionals and patients from an area of urban disadvantage: A qualitative study. BJGP Open. https://doi. org/10.3399/bjgpopen19X101676

Saaty, T. L. (1977). A scaling method for priorities in hierarchical structures. Journal of Mathematical Psychology, 15(3), 234-281. https://doi.org/10.1016/00222496(77)90033-5

Saaty, T. L. (1990). How to make a decision: The analytic hierarchy process. European Journal of Operational Research, 48(1), 9-26. https://doi.org/10.1016/03772217(90)90057-1

Saha, A. K., \& Agrawal, S. (2020). Mapping and assessment of flood risk in Prayagraj district, India: A GIS and remote sensing study. Nanotechnology for Environmental Engineering, 5(2), 11. https://doi.org/10.1007/s41204-02000073-1

Şahin, T., Ocak, S., \& Top, M. (2019). Analytic hierarchy process for hospital site selection. Health Policy and Technology, 8(1), 42-50. https://doi.org/10.1016/j.hlpt. 2019.02.005

Samani, Z. N., \& Alesheikh, A. A. (2019). Uncertainty modelling of citizen-centered group decision making using fuzzy-vikor case study: Site selection of healthcare services. ISPRS-International Archives of the Photogrammetry, Remote Sensing and Spatial Information Sciences XLII-4/W18(October). https://doi.org/10.5194/isprsarchives-XLII-4-W18-809-2019

Schuurman, N., Leight, M., \& Berube, M. (2008). A Web-based graphical user interface for evidence-based decision making for health care allocations in rural areas. International Journal of Health Geographics, 7(1), 49. https://doi.org/ 10.1186/1476-072X-7-49

Senvar, O., Otay, I., \& Bolturk, E. (2016). Hospital site selection via hesitant fuzzy TOPSIS. IFAC-PapersOnLine, 49(12), 1140-1145. https://doi.org/10.1016/j.ifacol.2016.07.656

Shahbod, N., Bayat, M., Mansouri, N., Nouri, J., \& Ghoddusi, J. (2020). Application of delphi method and fuzzy analytic hierarchy process in modeling environmental performance assessment in urban medical centers. Environmental Energy and Economic Research, 4(1), 43-56. https://doi. org/10.22097/eeer.2020.197686.1103

Shorabeh, S. N., Firozjaei, M. K., Nematollahi, O., Firozjaei, H. K., \& Jelokhani-Niaraki, M. (2019). A risk-based multicriteria spatial decision analysis for solar power plant site selection in different climates: A case study in Iran. Renewable Energy, 143, 958-973. https://doi.org/10.1016/j. renene.2019.05.063
Siddiqui, A. F., Wiederkehr, M., Rozanova, L., \& Flahault, A. (2020). Situation of India in the COVID-19 pandemic: India's initial pandemic experience. International Journal of Environmental Research and Public Health, 17(23), 8994. https://doi.org/10.3390/ijerph17238994

Soltani, A., Inaloo, R. B., Rezaei, M., Shaer, F., \& Riyabi, M. A. (2019). Spatial analysis and urban land use planning emphasising hospital site selection: A case study of Isfahan city. Bulletin of Geography, 43(1), 71-89. https://doi.org/ 10.2478/bog-2019-0005

Soltani, A., \& Marandi, E. Z. (2011). Hospital site selection using two-stage fuzzy multi-criteria decision making process. Journal of Urban and Environmental Engineering, 5(1), 32-43. https://doi.org/10.4090/juee.2011.v5n1.032043

Tripathi, A. K., Agrawal, S., \& Gupta, R. D. (2019). WPS Enabled SDI: An open source approach to provide geoprocessing in web environment. ISPRS Annals of Photogrammetry, Remote Sensing and Spatial Information Sciences, IV-5/W2(December). https://doi.org/10.5194/ isprs-annals-iv-5-w2-119-2019

Tripathi, A. K., Agrawal, S., \& Gupta, R. D. (2020b). Cloud enabled SDI architecture: A review. Earth Science Informatics, 13(2), 211-231. https://doi.org/10.1007/s12145020-00446-9

Tripathi, A. K., Agrawal, S., \& Gupta, R. D. (2020). A conceptual framework of public health SDI. In J. K. Ghosh \& I. da Silva (Eds.), Applications of geomatics in civil engineering: Lecture notes in civil engineering (Vol. 33, pp. 479-487). Springer. https://doi.org/10.1007/978-98113-7067-0_37

Vahidnia, M. H., Alesheikh, A. A., \& Alimohammadi, A. (2009). Hospital site selection using fuzzy AHP and its derivatives. Journal of Environmental Management, 90(10), 3048-3056. https://doi.org/10.1016/j.jenvman. 2009.04.010

Velez, F. F., Colman, S., Kauffman, L., Ruetsch, C., \& Anastassopoulos, K. (2021). Real-world reduction in healthcare resource utilization following treatment of opioid use disorder with reSET-O, a novel prescription digital therapeutic. Expert Review of Pharmacoeconomics \& Outcomes Research, 21(1), 69-76. https://doi.org/10.1080/14737167. 2021.1840357

Wang, Y. M., \& Chin, K. S. (2008). A linear goal programming priority method for fuzzy analytic hierarchy process and its applications in new product screening. International Journal of Approximate Reasoning, 49(2), 451-465. https://doi.org/10.1016/j.ijar.2008.04.004

Wang, Y. M., Elhag, T. M. S., \& Hua, Z. (2006). A modified fuzzy logarithmic least squares method for fuzzy analytic hierarchy process. Fuzzy Sets and Systems, 157(23), 3055-3071. https://doi.org/10.1016/j.fss.2006.08.010

Zolfani, S. H., Yazdani, M., Torkayesh, A. E., \& Derakhti, A. (2020). Application of a gray-based decision support framework for location selection of a temporary hospital during COVID-19 pandemic. Symmetry, 12(6), 886. https://doi.org/10.3390/sym12060886

Publisher's Note Springer Nature remains neutral with regard to jurisdictional claims in published maps and institutional affiliations. 